\title{
Effects of Orography on the Tail-End Effects of Typhoon Ketsana
}

\author{
F. Tan*, H.S. Lim and K. Abdullah \\ School of Physics, Universiti Sains Malaysia, 11800 Penang, Malaysia
}

\begin{abstract}
The study of tail-end effects of typhoon on orography is new to Malaysia. The current study used FY-2D satellite data to investigate the variation of selected parameters of the Typhoon Ketsana system. In situ data, obtained via the radiosonde technique, were used to verify the atmospheric conditions, whereas the Advanced Spaceborne Thermal Emission and Reflection Radiometer Global Digital Elevation Model was applied to determine the structure of the mountains in East Malaysia (EM). This study aimed to identify typhoon-terrain effects, in terms of wind, cloud, and rain of the tail-end effects of typhoon in a regional environment. The tail-end effects of Typhoon Ketsana were altered by the orography in EM such that a slow movement with higher rate of rainfall was distributed along the mountainous western region, and cloud classification distribution patterns were different before, during, and after the tail-end effects of the typhoon. The wind intensity increased with altitude and affected the larger atmosphere region over EM. Additionally, the location of the Sabah region puts it at a higher risk to the impact of the tail-end effect of typhoons compared with the Sarawak region due to its distance from the typhoon. This study concluded that the impacts of the tail-end effects of a typhoon can also be varied and enhanced by the orography.
\end{abstract}

Keywords: Cloud, orography, rain, tail-end effects, typhoon ketsana, wind.

\section{INTRODUCTION}

Tropical cyclones (TCs) can alter the synoptic scale circulation pattern throughout the entire troposphere, thereby forming perturbations in the planetary scale circulation pattern, which may have far-reaching implications in regions far from the center of TCs. This phenomenon strongly influences the regional rainfall pattern, even in countries that are not directly in the path of these cyclones. The western Pacific, including the northwest Pacific Ocean (NWP) and the South China Sea (SCS), are the most active cyclogenesis basins with an average of 27 cyclones per year, almost half of which reach typhoon intensity [1]. The most active months for cyclogenesis are from August to October (during the southwest monsoon period or the summer season) [2].

Typhoon tracks in the NWP are classified into three paths: straight-moving (SM), recurving (R), and northoriented (NO), as determined using k-means cluster analysis [3]. The SM typhoon path more commonly affects Southeast Asia (SEA). Therefore, one of the SM typhoons was selected in this study, which was called Typhoon Ketsana. Ketsana strongly affected SEA, destroying over 7.4 million structures (the highest number in the world) and killed more than 645 people (the third highest in the world). Furthermore, the typhoon caused 1.03 billion US\$ in economic losses (the ninth highest in the world), thus Ketsana was among the top ten catastrophes of 2009 [4].

The direct treatment of TCs is nonexistent in the Malaysian region, but most of the tropical storms formed over the western Pacific Ocean that move northwest from

*Address correspondence to this author at the School of Physics, Universiti Sains Malaysia, 11800 Penang, Malaysia; Tel: +604-653-3200/3198;

Fax: +604-657-9150; E-mail: fuyitan@yahoo.com
Sabah trigger the tail-end effects of TCs, which include strong winds, heavy rainfall, and rough seas in east Malaysia (EM), due to the location of EM between SCS and NWP. The effects depend on the intensity, position, and movement of the TC.

The tail effects of typhoons, such as heavy rainfall and strong winds, occasionally affect regions in Malaysia. Several studies have been performed on the impact of typhoons in Malaysia. First, the impact of a TC on the amount of rainfall in different parts of Malaysia was studied using 57 years of data (from 1951 to 2007) obtained from the Regional Specialized Meteorological Centre (RSMC) in Tokyo and rainfall data from the same period from selected principal meteorological stations in Malaysia, using a probability computation of the statistics [5]. Second, the impact of a TC at different locations on the rainfall in peninsular Malaysia from 1981 to 2007 was studied using 27 years of data from the Joint Typhoon Warning Centre (JTWC) and daily rainfall data from the same period from selected principal meteorological station in Malaysia, using probability computation of the statistics [6]. Third, an MTSAT -IR geostationary satellite was used to identify rain cloud clusters and rainfall chart data from meteorological stations in Malaysia to identify TCs that have affected Malaysian weather [7]. Fourth, rainfall distribution patterns due to the tail-end effects of typhoons were studied using an FY-2C geostationary satellite and weather radar echoes [8]. Lastly, wind strength was determined using wind speed charts from a few selected meteorological stations in EM [9]; the study was prompted by the destruction hundreds of houses, electric poles and trees, as well as telecommunication towers in west Sabah due to strong winds on the night of September 27, 2009. These five studies showed that the tail-end effects of TCs can have a 
considerable impact on the weather and environment in EM. Therefore, further studies on the effects of typhoon tail-ends are needed.

In general, the interior of EM is filled with high terrain, including the highest mountain in SEA, Mount Kinabalu (approximately 4,095 m), where orographic effects influence weather conditions. A sudden, significant change of the weather system in the synoptic scale, such as the appearance of a tropical cyclone, will alter the basic atmospheric state throughout the entire troposphere. Therefore, regional rainfall rates and distribution patterns will vary within the TC system.

Topography and orography are considered to be capable of changing the impact patterns of TCs, if the terrain is sufficiently high. Briefly, previous studies and reports on the tail-end effects of typhoons on Malaysia have not considered the orographic effects that may impact rainfall and wind patterns throughout Malaysia. Nonetheless, many studies on the orographic effects on typhoons have indicated that complex mountain structures play a crucial role in the rainfall and wind flow patterns. Therefore, the orographic effects must be taken into consideration. Understanding the characteristics of the mountains in Malaysia is essential in improving the forecast of flash floods and strong winds, as these natural disasters constantly influence the daily lives of Malaysians. This study focuses on the variation of tail-end effects (in terms of rain, wind, and cloud) of typhoon Ketsana due to orography.

\section{STUDY CASES FOR TROPICAL CYCLONES AFFECTED BY OROGRAPHY}

The orographic effect is defined as the way that mountains and other elevated terrain alter the prevailing weather conditions in a particular region. This effect can also refer to an atmospheric disturbance that is caused by, or related to, the presence of mountains or other high terrain. The orographic effect may cause mountain waves due to the air flow passing over a mountain or mountain range [10]. Additionally, wind velocity decreases near the surface due to surface roughness; therefore, wind velocity profiles are different for various terrain types [11]. In the continental region, the rough, irregular grounds and man-made obstructions slow down the air near the surface and reduce wind velocity $[12,13]$. Over a city or over a rough terrain, the wind gradient effect could cause a reduction of $40 \%$ to $50 \%$ of the geostrophic wind speed. On the other hand, the reduction may be only $20 \%$ to $30 \%$ over open water or ice $[14,15]$.

With understanding of the basic orographic effects, a powerful synoptic system, such as a typhoon activity, will deliver more interesting results on the interaction between typhoon and orographic effects. Several study cases have focused on the effect of orography on typhoon activity. In studying the case of Typhoon Herb (1996) that occurred near Taiwan, Wu and Yen [16] found that the vertical motion, heating rate, and the slope of the mountains played a crucial role in forced lifting, a result of the interaction between the typhoon's circulation and Taiwan's mountainous terrain. They found that the Central Mountain Range, with an average elevation of more than 2,000 $\mathrm{m}$ and more than 200 peaks that rise higher than $3,000 \mathrm{~m}$, only has a minor impact on the storm typhoon track, but will still enhance the rainfall rate over Taiwan. The increase in rainfall during this period was proven by their simulation model, through which they found that the model and terrain resolution have nearly equivalent roles in affecting the amount of rainfall. Thus, the effect of the topography was presented when Typhoon Herb passed Taiwan. The percentage of the rainfall near Mount A$\mathrm{Li}$ in seven different experiments showed a coincidental increase in the rainfall amount from $15 \%$ to $50 \%$ for the $24-$ hour average accumulation.

Typhoon track deflection depends on the orographic effects as well as the intensity and speed of the moving vortex [17-20]. Previous studies have stated that orography is a key factor in improving the accuracy of typhoon track prediction, given than mountainous areas may deflect the typhoon track.

Orography plays a key role in rainfall distribution patterns [21-26]. The track of cyclones directly affects the patterns of precipitation distribution. However, the topography may modify and enhance typhoon rainfall, as observed in $\mathrm{Wu}$ and Yen's simulation model, which predicted that rainfall accumulation will be greater in higher terrains than in lowland regions, even though the rainfall amount is a bit overestimated. Colón-Pagán [27] found that the passage of tropical cyclones over mountainous islands may result in a maximum rainfall rate at the higher mountain regions due to orographic effects. Colón-Pagán conducted four simulation experiments, one of which showed the close match between the rain accumulation with the observed measurements because a smooth rainfall distribution was found in three study locations of Puerto Rico (the first one towards the east of Sierra de Cayey; the second, concentrated in the most higher-central region of the island; the third region, towards the west of this elevated region) as the simulation experiment for the accumulation rainfall among these study locations were not over- or underpredicted on where the storm made landfall and on the regions of high elevation. Therefore, this result implied that the landfall location and high elevation region is very important factor which can affect the simulation result as there are certain relationship exist in between rain event and the landfall location and high elevation region.

Huang and $\mathrm{Wu}[28]$ also found that high mountain ranges not only cause the track to deflect from its original path, these also alter the typhoon's intensity, structure, and rainfall patterns. The high resolution of the topography in Taiwan is necessary to improve the accuracy of rainfall rate prediction, due to the close relationship among the variations in the typhoon features when associated with the topography [29]. Liang et al. [30] also reported that the rainfall of a typhoon activity might be affected by the topography. A recent study by Tan et al. [31] revealed that the impacts of Typhoon Ketsana (2009) in Indochina were significantly affected by the topography because rainfall tends to be distributed and delayed over the high mountain regions, resulting in heavy or high rate of rainfall. They also found that wind flow during this typhoon period will change its direction for the lower- and upper-levels of the troposphere, upon encountering high mountains. In addition, the cloud classification for the low and middle, high, and vertical development clouds will be affected by high mountains. 


\section{STUDY AREA}

EM consists of the Malaysian states of Sabah and Sarawak. The total area of EM is $197,177 \mathrm{~km}^{2}$, mostly comprising lowland rainforests with areas of mountainous rainforests toward the inner regions [32]. EM is a part of Borneo, which occupies approximately $26 \%$ of the island. The other $73 \%$ is Indonesian territory, whereas the remaining $1 \%$ belongs to Brunei (refer to Fig. 1). Fig. (1) shows the solid-contour topography map of these regions, which indicates the lowlands and high mountainous regions. The three red triangles located in Sabah and Sarawak, respectively, indicate the mountains of interest in this study, listed in Table 1. The highest mountain range in EM is the Crocker Range, which is the backbone of Sabah that divides the state in half. Mountain ranges in the east tend to follow the north-south or northeast-southwest direction, with varying heights ranging from about $1,000 \mathrm{~m}$ to $4,000 \mathrm{~m}$, with the highest peaks reaching 4,095.2 $\mathrm{m}$ at the highest mountain in the country, Mount Kinabalu. Sarawak is divided into coastal lowlands, undulating hills with heights reaching about $300 \mathrm{~m}$, and the mountain highlands that extend to the Kalimantan border [33].

\section{DATA AND METHODOLOGY}

The current study analyzed the impacts of the tail effects of Typhoon Ketsana, which occurred on September 25 and
26, 2009 on EM. Radiosonde data were acquired from http:// weather.uwyo.edu/upperair/sounding.html. Fengyun satellite data for the products of precipitation $\left(0.1^{\circ} \mathrm{X} 0.1^{\circ}\right.$ resolution $)$, cloud $\left(0.1^{\circ} \mathrm{X} 0.1^{\circ}\right.$ resolution), and atmospheric motion vector products $\left(1^{\circ} \mathrm{X} 1^{\circ}\right.$ resolution) were acquired from http://satell ite.cma.gov.cn/arssen. The Advanced Spaceborne Thermal Emission and Reflection Radiometer Global Digital Elevation Model (ASTER GDEM), with a resolution of 30 $\mathrm{m}$, was acquired from http://asterweb.jpl.nasa.gov/gdemwist.asp. Finally, NOGAPS data for wind (resolution of $2^{\circ} \mathrm{X} 2^{\circ}$ for the surface, and $1^{\circ} \mathrm{X} 1^{\circ}$ for 850 and $700 \mathrm{mb}$ ) was acquired from http://www.nrlmry.navy.mil/flambe/7seas/7se as.html.

The detailed steps of the product generation, including the precipitation estimation, atmospheric motion vector, and cloud classification from the FY2D satellite, may be found in [34]. Although the China Meteorological Administration lists eight cloud classifications, only a few of these were discussed in this study for determining the variations between low-, middle-, and high-level clouds and their interaction with certain weather conditions. Some of these classes have been combined into three groups: 1) cumulonimbus clouds (with vertical development); 2) cirrostratus and cirrus clouds (high clouds); and 3) stratocumulus or altocumulus and nimbostratus or altostratus (low and middle clouds). Low and middle clouds are

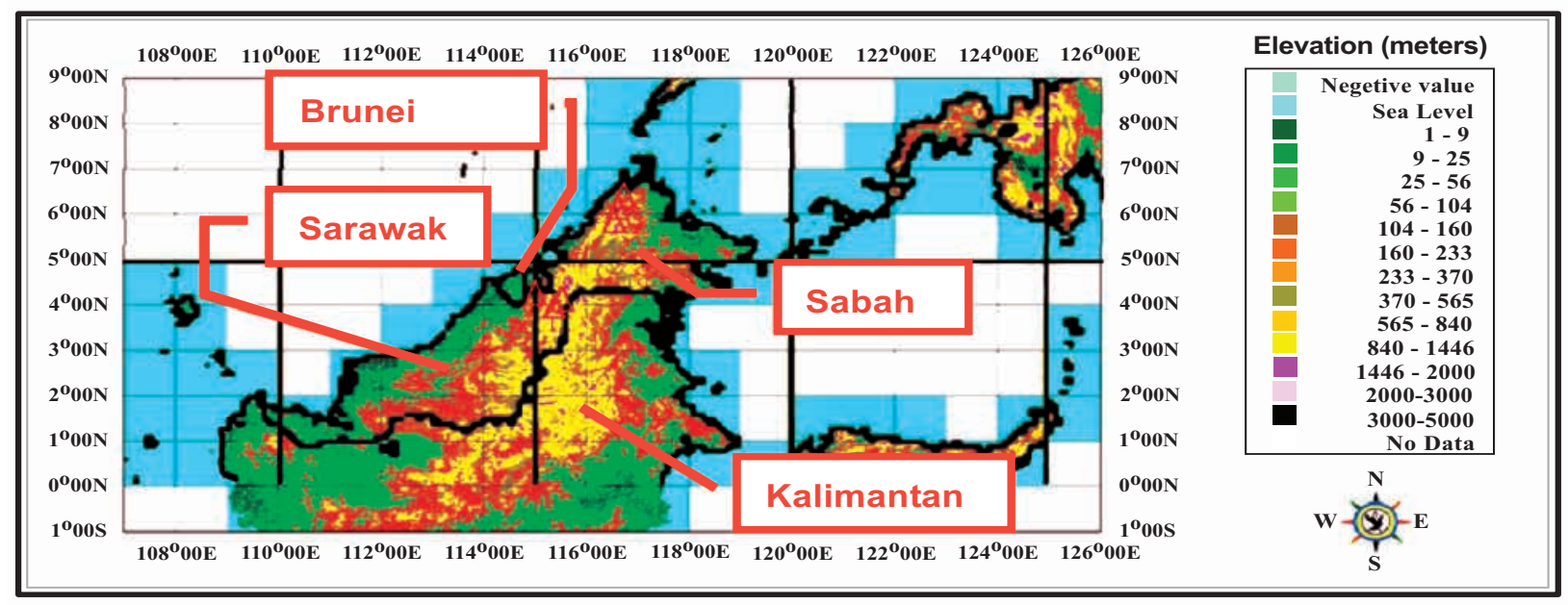

Fig. (1). Digital elevation model of EM, edited to include latitude $1^{\circ} \mathrm{S}-9^{\circ} \mathrm{N}$ and longitude $107^{\circ} \mathrm{E}-126^{\circ} \mathrm{E}$. The inland of EM has numerous high mountain ranges that extent to most part of Kalimantan, Indonesia. Red triangles represent the mountains selected in this study, which are listed in Table $\mathbf{1}$.

Table 1. Elevation and Position of the Mountains in EM*

\begin{tabular}{|c|c|c|c|c|}
\hline \multirow{2}{*}{ State of East Malaysia } & Mountain Name & Elevation (m) & Latitude $\left({ }^{\circ} \mathbf{N}\right)$ & Longitude $\left({ }^{\circ} \mathbf{E}\right)$ \\
\hline \hline \multirow{2}{*}{ Sabah } & Kinabalu & $4,095.2$ & $\sim 6.08$ & $\sim 116.55$ \\
\cline { 2 - 5 } & Trusmadi & $2,642.0$ & $\sim 5.55$ & $\sim 116.52$ \\
\hline \multirow{3}{*}{ Sarawak } & Tambuyukon & $2,579.0$ & $\sim 6.22$ & $\sim 116.65$ \\
& Murud & $2,423.0$ & $\sim 3.91$ & $\sim 115.50$ \\
& Mulu & $2,376.0$ & $\sim 4.04$ & $\sim 114.93$ \\
& Batu Lawi & $2,046.0$ & $\sim 3.88$ & $\sim 115.38$ \\
\hline
\end{tabular}


grouped together because of the limitations of the cloud classification technique for both.

A global digital elevation model from the ASTER satellite was produced to represent only a small area, with each GDEM image or product saved in a GeoTIFF file format. Then, a number of GeoTIFF files were merged into a single GeoTIFF image file using ENVI version 4.5 in order to reproduce a larger region in a contour plot. The GDEM images of EM were downloaded in 115 GeoTIFF files. After merging these single images into their respective study areas, we used PCI geometrical version 10.3.0 to plot a solid contour elevation map for the study area.

Data on the upper air observation from radiosonde and wind information from NOGAPS were directly downloaded from the website and then modified to produce a better image to help understand the images.

\section{RESULTS AND DISCUSSIONS}

During cyclogenesis, atmospheric dynamics are complicated because cyclones are synoptic systems. In strong TCs, any typhoon activity has strong influences on the entire tropospheric circulation and the weather of the surrounding regions. Thus, Skew-T and hodograph diagrams from stations at Kota Kinabalu, Sabah and Bintulu, Sarawak were used in this study to understand the impact of Ketsana on EM (Figs. 2, 3). From the observation of FY-2D geostationary satellite images, heavy rains struck EM three times during the period between 0515 UTC and 1615 UTC on September 25, 2009 (Fig. 4) and between 2015 UTC of September 25, 2009 and 1115 UTC on September 26, 2009 (Fig. 5).

However, the third period (1215 UTC to 2315 UTC on September 26, 2009) was excluded in this study because the tail effect of the interaction between Ketsana and the orography was not significant. Hence, sounding data for 0000 UTC and 1200 UTC measured from September 25 to 26 at Kota Kinabalu, Sabah were acquired to study the atmospheric conditions. Sounding data, or the atmospheric behavior, were used to enhance and describe the satellite data (precipitation) to help us understand the impact of Ketsana on EM.

Before the tail effect reached EM on September 25, 2009, at 0000 UTC, the sounding data from the Kota Kinabalu station (Fig. 2a (i)) showed that the lift was -3.88 , indicating an approaching thunderstorm. The greater the negative number of the lift, the better the chance of thunderstorms, and the greater the threat of having inclement weather. In addition, the convective available potential energy (CAPE) was $1,786 \mathrm{Jkg}^{-1}$, indicating an unstable atmosphere. The convective inhibition (CINS) from the Skew-T showed a value of $-45.1 \mathrm{Jkg}^{-1}$, which indicated the developing convection that could be overcome for storm initiation. Alternatively, the sounding data from Bintulu station (Fig. 3a (i)) showed that the lift value was -0.07 , and the CAPE was $47.33 \mathrm{Jkg}^{-1}$, indicating that the region had an undeveloped thunderstorm at the time. The CINS value, which was as high as $-227.12 \mathrm{Jkg}^{-1}$, implied that convection was not likely to develop, because a value greater than 100 $\mathrm{Jkg}^{-1}$ to $200 \mathrm{Jkg}^{-1}$ of CINS is usually too large to overcome [35]. These weather conditions were unlikely at the Kota
Kinabalu station because the Bintulu region was far from the storm center. Additionally, the vertical wind shear varied with the height, ranging from $1,000 \mathrm{mb}$ to approximately $450 \mathrm{mb}$ (Fig. 2a (i) and (ii)). Fig. (2a) (ii) clearly shows the wind variation. Although the vertical wind shear was not as strong due to the spinning updraft, a deep convection was believed to exist in this air column. Thus, we anticipated that a thunderstorm was developing due to the tail effect of Ketsana, which was then located over the middle part of the Philippines. Fig. (3a) (ii), a general view from the hodograph, shows the veer wind pattern in the Bintulu region, which had a similar wind pattern to that in Kota Kinabalu.

Based on Fig. (4), the presence of Ketsana over the Philippines strongly influenced the atmospheric circulation, and as a result, the weather of EM also changed. From the FY-2D geostationary satellite data, the rainfall covered most regions of EM from 0515 UTC to 1615 UTC on September 25, 2009. Rainfall formed rapidly over EM, and the high terrains in the northern part of Sabah experienced heavy rainfall (refer to Table 1), including Mount Kota Kinabalu (4,095 m), Trusmadi (2,642 m), and Tambuyukon (2,579 m), as well as parts of the Sarawak region, including Mount Murud (2,423 m), Mulu (2,376 m) and Batu Lawi (2,046 m). During the formation of a rain cloud from 0515 UTC to 0915 UTC, rainfall was distinctly distributed across western EM. The light brown and yellow colors in Fig. (1) indicate the altitude of the EM topography, with $565 \mathrm{~m}$ to $840 \mathrm{~m}$ and 840 $\mathrm{m}$ to $1,446 \mathrm{~m}$, respectively. The cloud base over the Kota Kinabalu region, represented by the LCL, was approximately $926 \mathrm{mb}$ (approximately $744 \mathrm{~m}$ ) at $0000 \mathrm{UTC}$ and $932 \mathrm{mb}$ (approximately $685 \mathrm{~m}$ ) at 1200 UTC on September 25, 2009 (Figs. 2a (i), b (i)). The cloud base over the Bintulu region was $897 \mathrm{mb}$ (approximately $1,177 \mathrm{~m}$ ) at $0000 \mathrm{UTC}$ and 918 mb (approximately $814 \mathrm{~m}$ ) at 1200 UTC (Fig. 3a (i), b (i)). The cloud base height over Kota Kinabalu and Bintulu also decreased with time from 0000 UTC to 1200 UTC on September 24. However, the cloud base at Kota Kinabalu was lower than that of the Bintulu region because the former was closer to the storm center. Thus, the high mountain ranges in EM (refer to Fig. 1) disturbed and blocked the movement of the rain cloud at 0000 UTC and 1200 UTC; the cloud base at that moment was low enough. Fig. (3) shows the rainfall patterns that were significantly affected by the high terrain over Sabah and Sarawak at 0715 UTC. The rainfall pattern was disturbed by the mountain ranges along central EM.

The atmospheric conditions over Kota Kinabalu at 1200 UTC on September 25, 2009 were more unstable than those in the preceding twelve hours, as indicated by comparing Fig. (2a (i), b (i)), where the value of the CAPE increased from $1,786 \mathrm{Jkg}^{-1}$ to $2,470 \mathrm{Jkg}^{-1}$, and the CINS value was reduced from $-46.1 \mathrm{Jkg}^{-1}$ to $-4.65 \mathrm{Jkg}^{-1}$, whereas the CAPE and the CINS was $0 \mathrm{Jkg}^{-1}$ at the Bintulu station at 1200 UTC due to incomplete data. The decrease in CINS is generally caused by the following: 1) daytime heating, 2) synoptic upward forcing, 3) low-level convergence, 4) low-level warm air advection (especially if accompanied by higher dew points) and the reduced CINS in the late afternoon [36]. EM faced daytime heating from morning to late afternoon, and low-level convergence was formed (Fig. 2b (ii) shows 


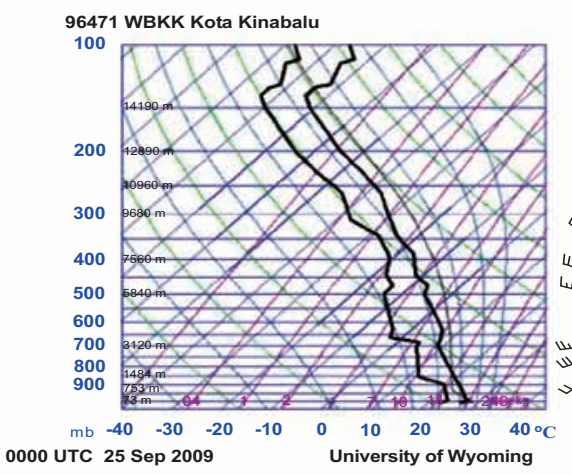

a(i)

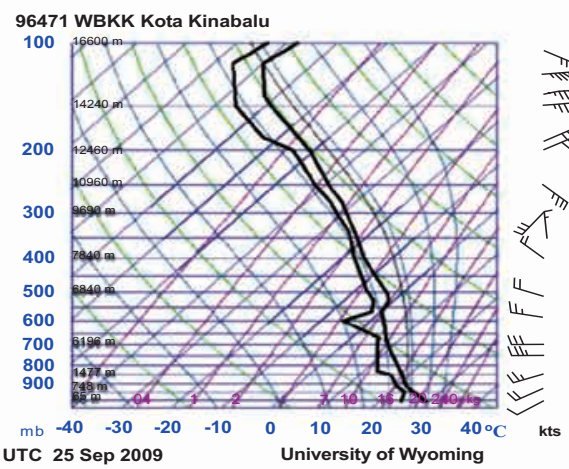

$b(i)$

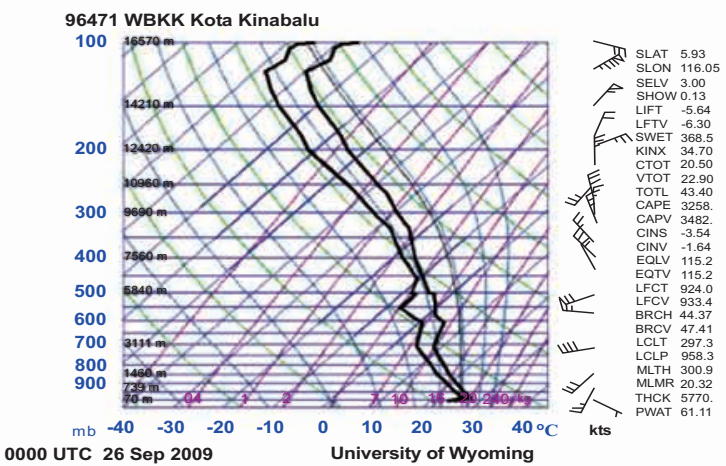

$\mathrm{c}(\mathrm{i})$

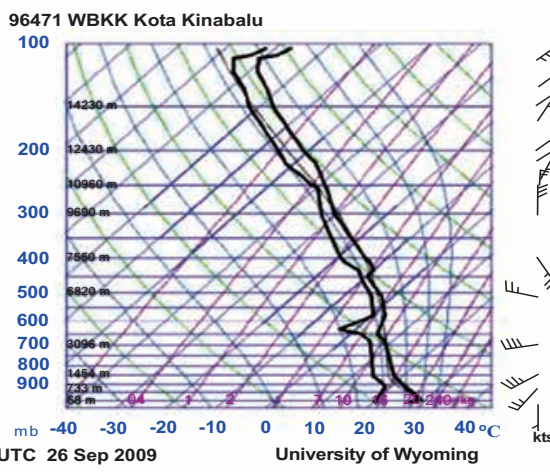

d(i)
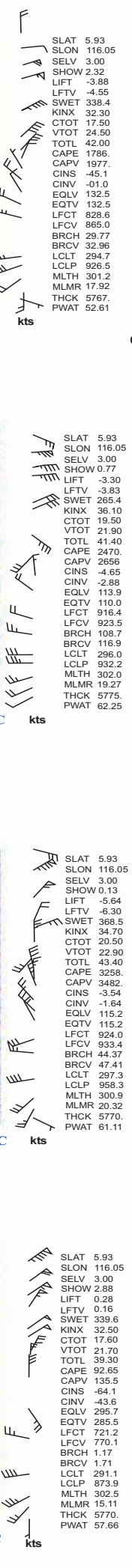

0000 UTC 25 Sep 2009

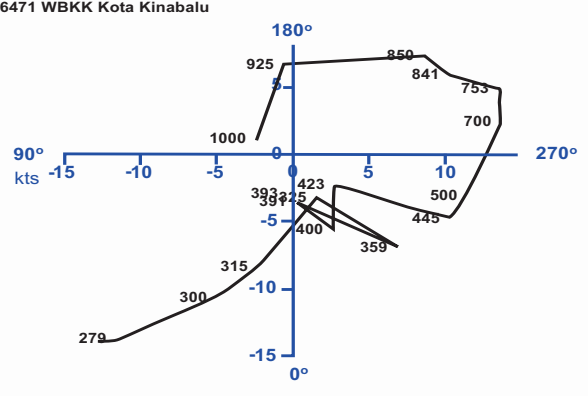

a(ii)

1200 UTC 25 Sep 2009

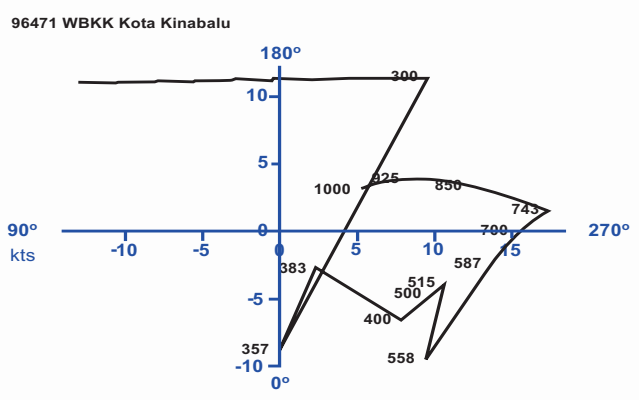

b(ii)

96471 WвкK Kota Kinabalu

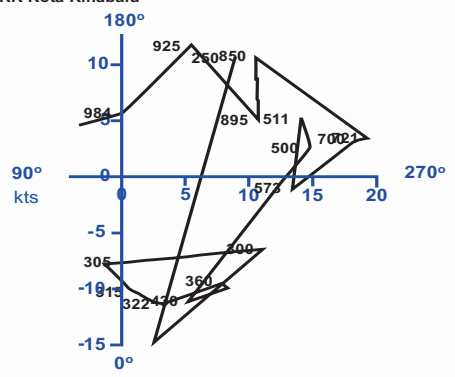

0000 UTC 26 Sep 2009

c(ii)

1200 UTC 26 Sep 2009

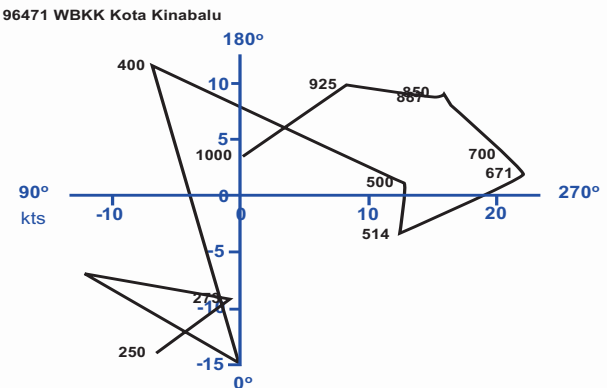

University of Wyoming

d(ii)

Fig. (2). Skew-T diagrams on the instability of the atmosphere. The hodographs display the change in the wind speed and direction with height (vertical wind shear). Four charts are plotted at 0000 and 1200 UTC for September 25 to 26, 2009 to show the variation in the atmosphere at Kota Kinabalu, Sabah during the development of Ketsana. These data were provided by the University of Wyoming. 


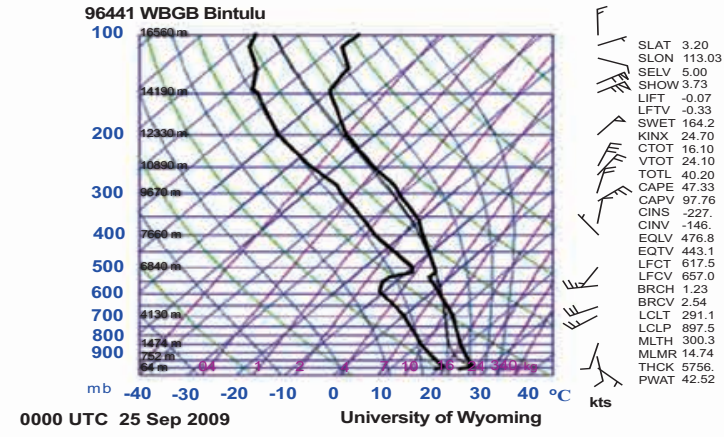

a(i)

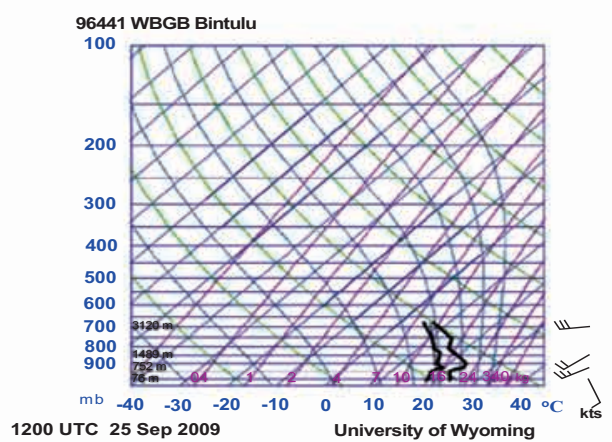

b(i)

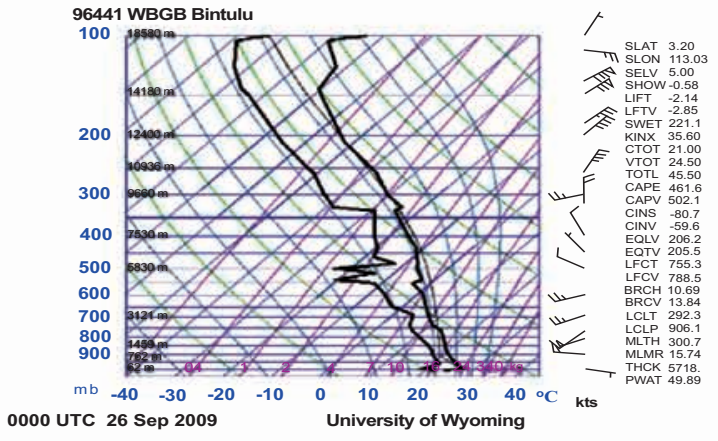

c(i)

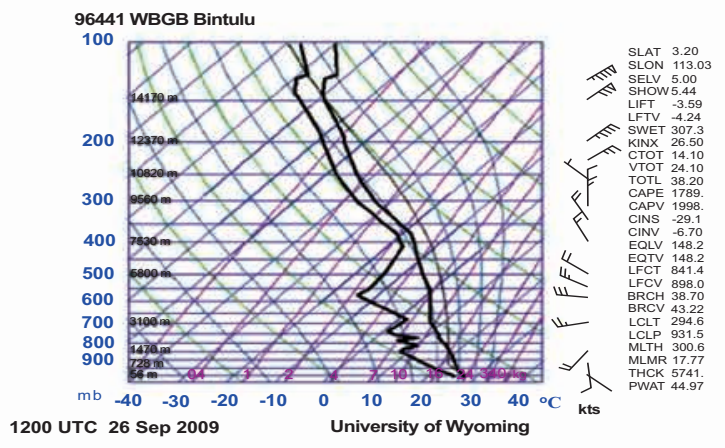

d(i)

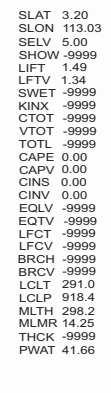

non-hodograph data

b(ii)

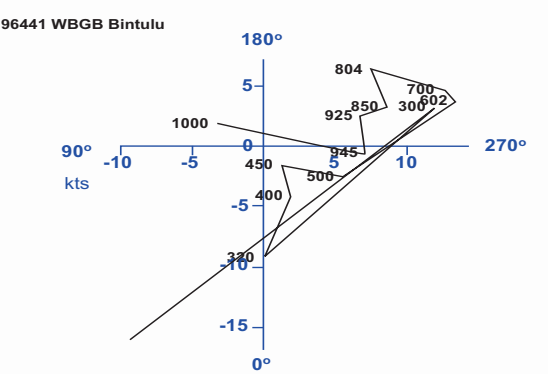

0000 UTC 26 Sep 2009

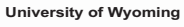

c(ii)

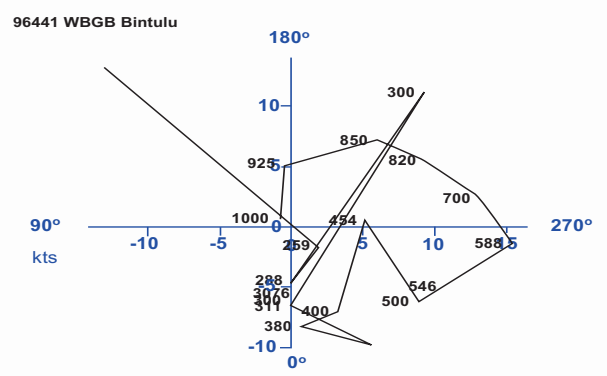

1200 UTC 26 Sep 2009

University of Wyoming

d(ii)

Fig. (3). Skew-T diagrams on the instability of the atmosphere. The hodographs display the change in the wind speed and direction with height (vertical wind shear). Three charts are plotted at 0000 and 1200 UTC for September 25 to 26, 2009, except 1200 UTC on September 25 due to incomplete data, to show the variation in the atmosphere at Bintulu, Sarawak during the development of Ketsana. These data were provided by the University of Wyoming. 


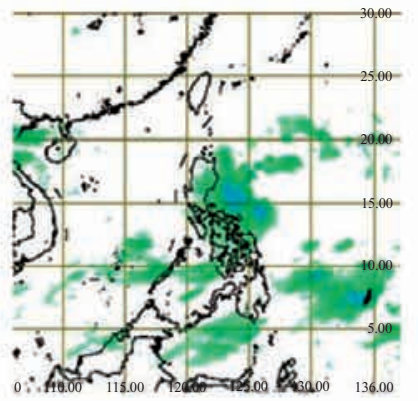

0515 UTC

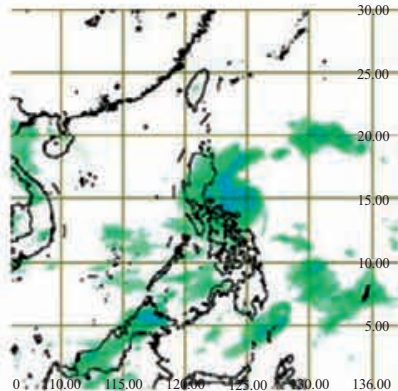

0915 UTC

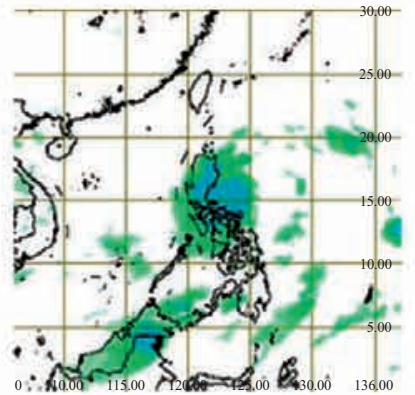

1315 UTC

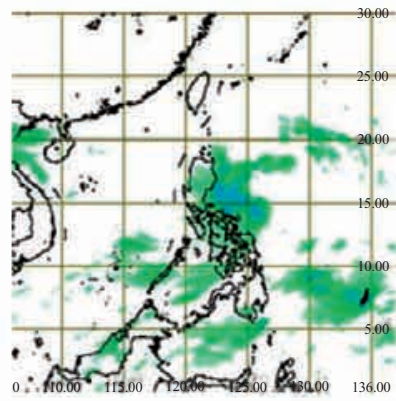

0615 UTC

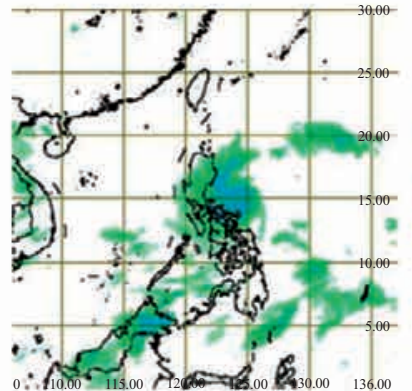

1015 UTC

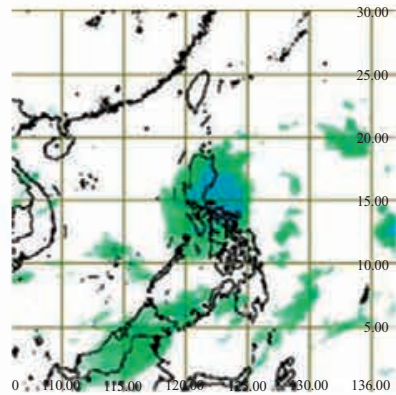

1415 UTC

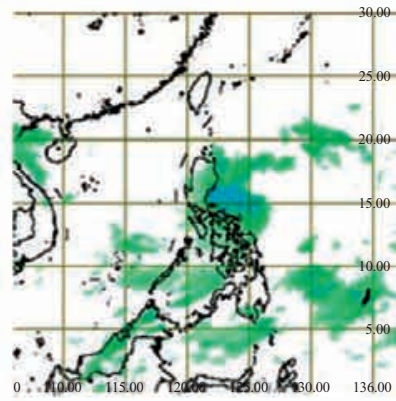

0715 UTC

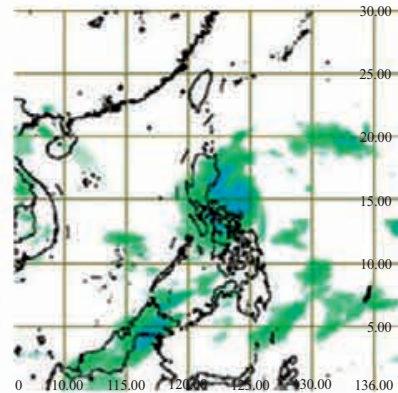

1115 UTC

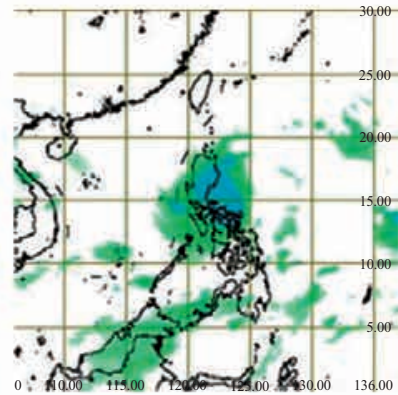

1515 UTC

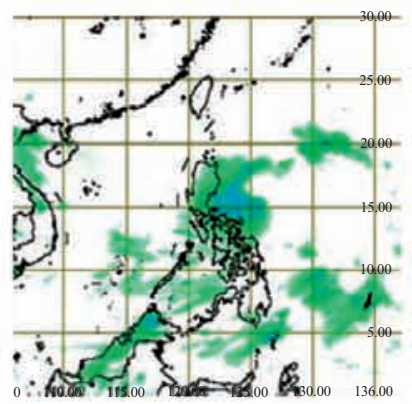

0815 UTC

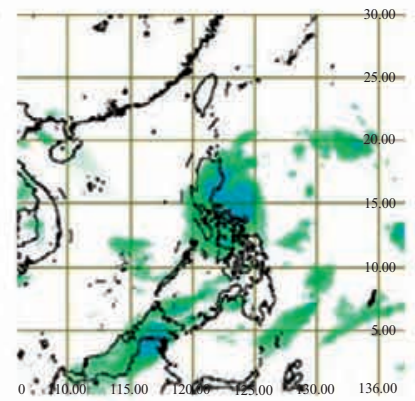

1215 UTC

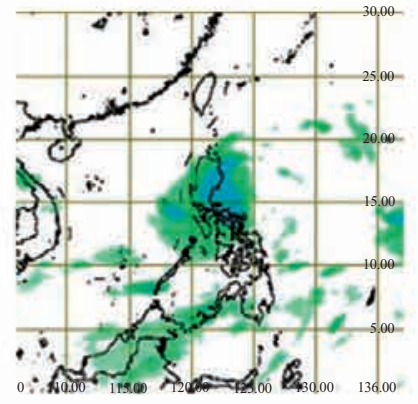

1615 UTC

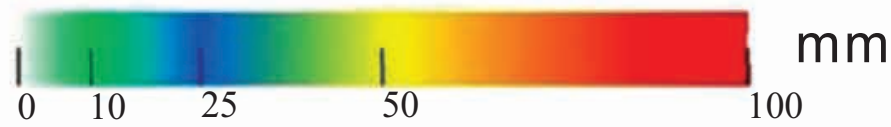

Fig. (4). Rainfall (in mm) images from 0515 UTC to 1615 UTC on September 25, 2009 were obtained from the FY-2D geostationary satellite. The rainfall distribution patterns varied with time. The significant synoptic variation in the atmosphere due to the development of Ketsana is clearly seen during this period. The storm was located in the Philippines, but the effect of the storm tail reached EM.

the wind in high upward motion). Obviously, the dew point was high at that time (Fig. 2b (i)). Therefore, these conditions showed the decrease in the CINS, which triggered the thunderstorm. Consequently, a thunderstorm was anticipated at this moment because the time at the Kota Kinabalu station at 1200 UTC was 08:00 PM Malaysian time, the time at which thunderstorms tend to occur in Malaysia. Additionally, rainfall images in Fig. (4) showed rainfall near Sabah and Sarawak, supporting the statement above.

Initially, heavy rainfall developed over the high mountains of northwest Sabah, then the rain distribution area grew larger and moved southward. Subsequently, the storm was disturbed by the mountains at northern Sarawak (refer to images in Fig. 4), so that the heavy rainfall tended to move between the mountains in Sabah and Sarawak (see Table $\mathbf{1}$ and Fig. 1). The rainfall distribution variations was determined by the rainfall cloud base because the cloud base over Kota Kinabalu was between 685 and 744 m (Figs. 2a (i) and $\mathbf{b}$ (i)) and between 814 and $1,177 \mathrm{~m}$ (Fig. 3a (i) and b (i)) in Bintulu. Hence, when the cloud base interacted with the terrains (Fig. 1), the high mountain ranges over EM played an important role in the rainfall distribution patterns. The rainfall in the following hour at 1200 UTC was still trapped by the mountain ranges, until the atmospheric circulation force was strong enough to move the rain cloud forward. The images in Fig. (4) show that the rain pattern moved forward in a slow motion.

The heavy rain over the northern Sabah region was caused by the following factors. First, Sabah is surrounded 


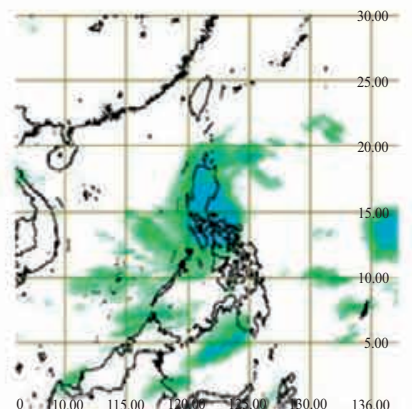

2015 UTC

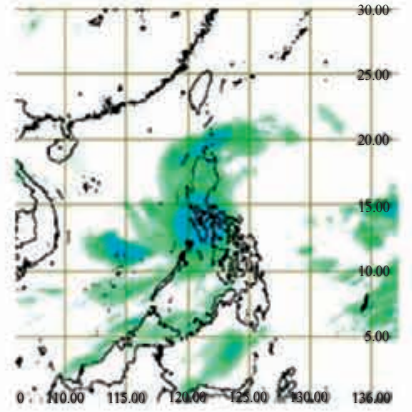

0015 UTC

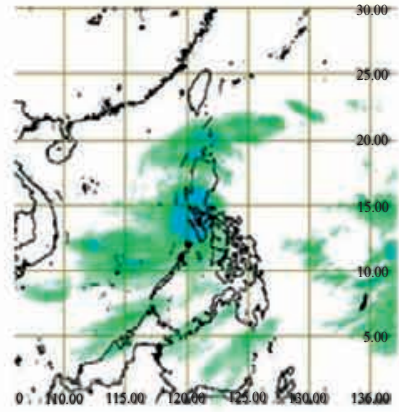

0415 UTC

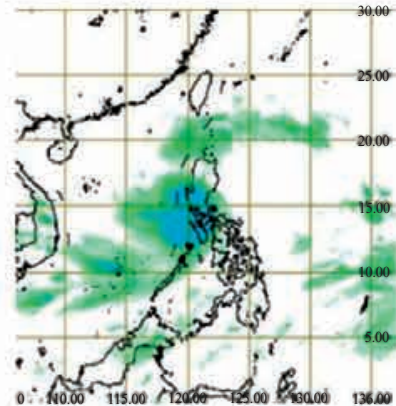

0815 UTC

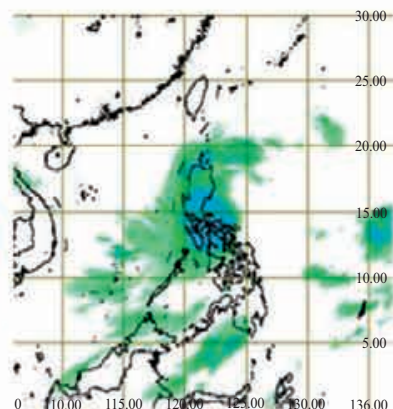

2115 UTC

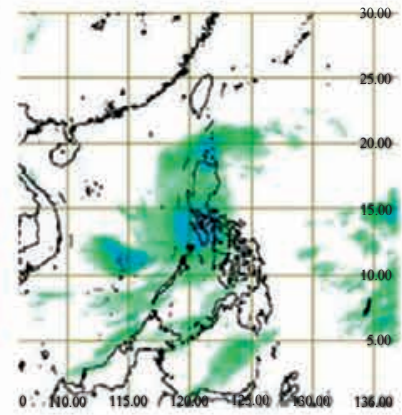

0115 UTC

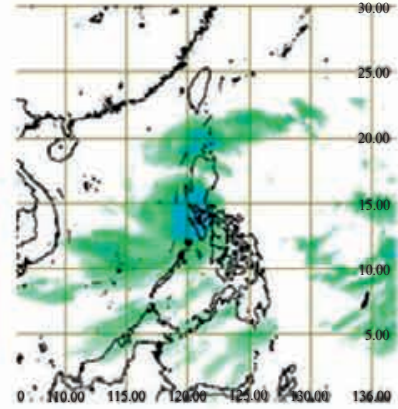

0515 UTC

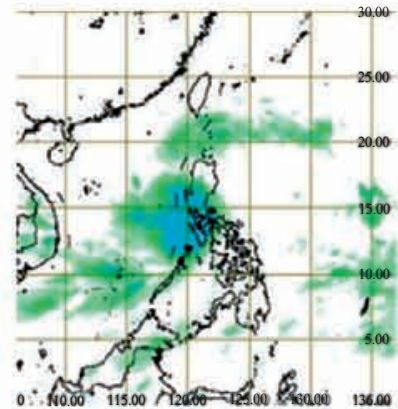

0915 UTC

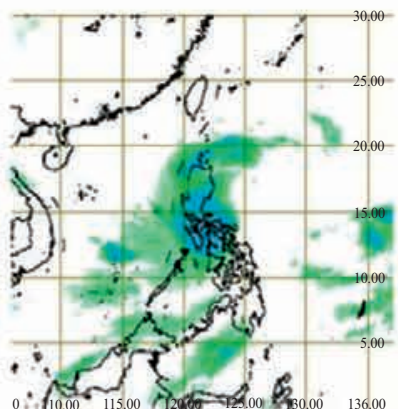

2215 UTC

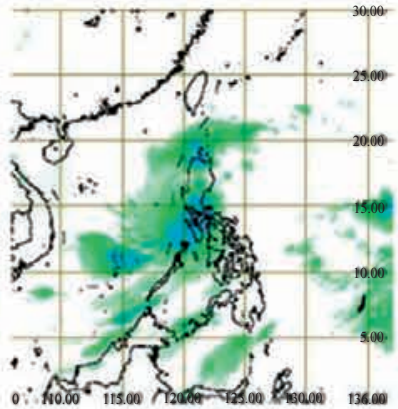

0215 UTC

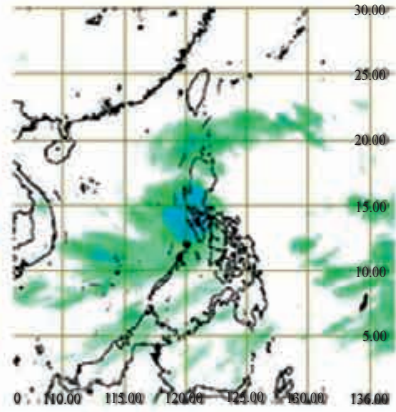

0615 UTC

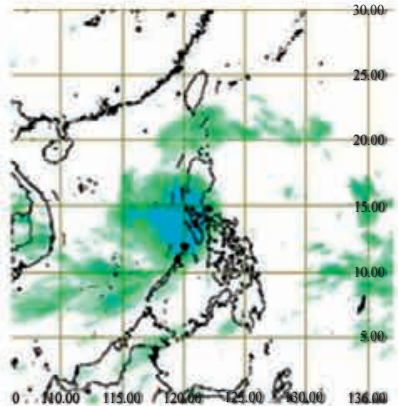

1015 UTC

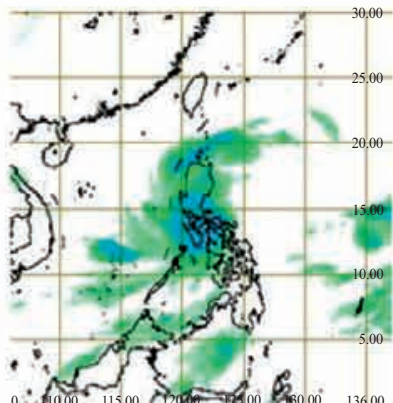

2315 UTC

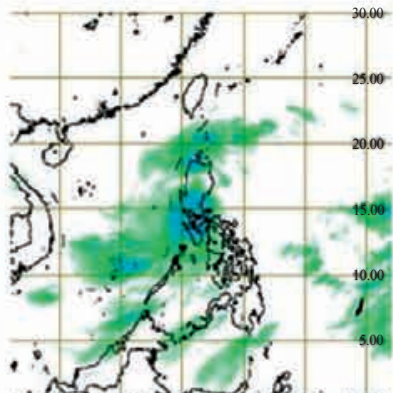

0315 UTC

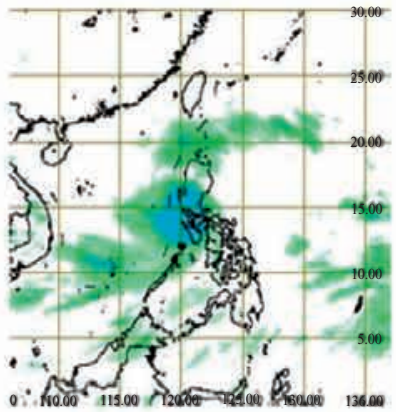

0715 UTC

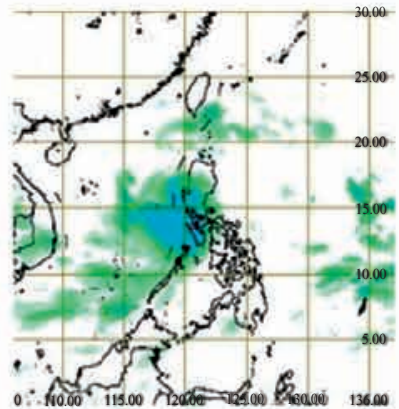

1115 UTC

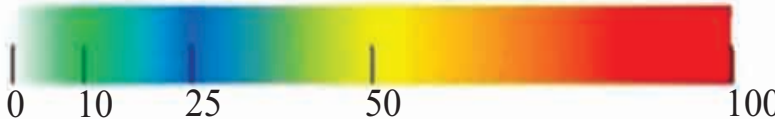

$\mathrm{mm}$

Fig. (5). Rainfall (in mm) images from 2015 UTC September 25, 2009 to 1115 UTC September 26, 2009 were obtained from the FY-2D geostationary satellite. At the time, the storm had landfall in the Philippines, passed through it, and continued to travel westward to the SCS. This period is the second time that the cyclone tail has affected EM.

by open seas, which may cause extreme moisture when the typhoon is near the region. This phenomenon was confirmed with obtained sounding data with a Skew-T diagram from 0000 UTC to 1200 UTC on September 25, 2009 (Fig. 2a (i), b (i)), which showed that the dew point temperature and environment temperature line were nearing each other. Therefore, high amounts of moisture upstream moved toward EM and then caused the relative humidity to increase 
from approximately $70 \%$ to $90 \%$ at ground surface; the increase continued with altitude until about $1.5 \mathrm{~km}$. Second, the large amount of water vapor brought by the tail effect of Ketsana may have been a contributing factor. This phenomenon was supported by the increase in value from $52.61 \mathrm{~mm}$ to $62.25 \mathrm{~mm}$ in the precipitable water for the entire sounding (PWAT) in Fig. (2a) (i) and b (i). Fig. (6) also shows that the air circulation was moving toward the typhoon system, indirectly pushing the water vapor to EM. Finally, the rainfall event was more distinct over the mountain ranges because the mountain structure could force the water vapor above the mountains where it may finally condense to form a cloud, as supported by [22]. Figs. $(\mathbf{4}, \mathbf{5})$ also show the tendency of the rainfall distribution pattern to be heavily distributed along the mountain regions, whereas Figs. $(6,7)$ also show that the air circulation was moving toward the typhoon system so it directly forced the air upslope to the top of the mountain as the tail effect of the typhoon came ashore and quickly rose to condense into a raining cloud (Figs. 9a, b). Although the cloud base might be blocked or slowed down by the high terrain, the clouds may still pass over the high regions because of external factors outside the typhoon. However, the rainfall weakened due to the lack of water vapor supplied in the inland regions (refer to 1315 UTC to 1615 UTC in Fig. 4).

The Ketsana tail effects on EM (Fig. 5) were more significant in the second round than in the first round (Fig. 4). Fig. (5) shows that the outer circulation of Ketsana indicated the movement of the rainfall distribution toward EM; the rainfall separated from the storm system, especially during the period from 2015 UTC to 2315 UTC on September 25. After 0215 UTC on September 26, the second tail effect moved to EM, whereby the rainfall reached the EM shoreline. At 0000 UTC September 26, the LCL over Kota Kinabalu was approximately $958 \mathrm{mb}$ (about $442 \mathrm{~m}$ ), so the cloud base at this time was low, whereas the cloud motion was greatly disturbed by the mountain ranges over Sabah (refer to Fig. 2c (i)). On the other hand, the LCL over the Bintulu region was $906 \mathrm{mb}$ (approximately $943 \mathrm{~m}$ ) and was also influenced by the mountains in Sarawak (refer to Fig. 3c (i)). The LFC is the level at which a lifted parcel of air will become equal in temperature to that of the ambient temperature.

The LFC in Kota Kinabalu was only $924 \mathrm{mb}$ (approximately $730 \mathrm{~m}$ ) at 0000 UTC 26 September. The difference between the LCL and LFC in Kota Kinabalu was only $288 \mathrm{~m}$ (between 442 and $730 \mathrm{~m}$ ), which indicated that deep convection existed in this column $[37,38]$. The LFC in Bintulu was $755 \mathrm{mb}$ (approximately 2,494 m), which was higher in altitude than in the Kota Kinabalu region. The difference between the LCL and LFC in Bintulu was 1,551 $\mathrm{m}$ (between $943 \mathrm{~m}$ and 2,494 m). However, the LFC values in both regions indicated that thunderstorms easily formed and remained over these regions. This statement is supported by another study, which stated that if LFC heights are lower than $3,000 \mathrm{~m}$ or more than $700 \mathrm{mb}$, thunderstorms will be easily formed [39].

The Skew-T in Fig. (3c) (i) indicates that the low-level troposphere condition in the Kota Kinabalu region contained very high relative humidity at the ground up to $950 \mathrm{mb}$. The
CAPE value of $3,258 \mathrm{Jkg}^{-1}$ proved that the atmosphere in this region was very instable. The high negative value for lift (5.64) and the high positive value for the Sweat Index (SI) (368.5) indicated that severe weather had arrived. This set of symptoms was due to the tail effect of Ketsana. The hodograph at 0000 UTC (Fig. 2c (ii)) showed that the wind pattern along the troposphere from the surface to the top was very complicated, but veering wind could still be distinguished. The wind speed between 700 and $300 \mathrm{mb}$ was also strong compared with the previous 12 and $24 \mathrm{~h}$, because the tail effect of Ketsana was more significant at this moment (this phenomenon can be seen by comparing the rainfall patterns in Figs. 4, 5). Weather conditions in the Bintulu region were more stable than those in Kota Kinabalu as indicated by the obtained results, in which the CAPE was $385 \mathrm{Jkg}^{-1}$, the lift was -2.14 , and the SI was 224 (Fig. 3c (i)) in the former region. Fig. (3c) (ii) shows a weak wind between 500 and $350 \mathrm{mb}$ and a strong vertical wind shear at the upper level (lower than $300 \mathrm{mb}$ ), which may trigger the formation and development of thunderstorms.

The variation of the rainfall distribution was dependent on the structure of the EM topography, especially the mountains at the Sabah region (Table 1). At 2015 UTC (Fig. 5), rainfall covered the northern part of Sabah, and the cloud base reached the Crocker Range in the north-south and the northeast-southwest path and then descended over Mount Kinabalu from 2115 UTC to 2315 UTC. Mount Trusmadi and Mount Tambuyukon also influenced the cloud movements and indirectly changed the rainfall distribution patterns. The rainfall patterns tended to be distributed near the base of the mountains on the mountain structure in a northeast-southwest path (2015 UTC to 2315 UTC September 25). Consequently, the rain did not fall in the middle or inland of Sabah at first because the rain cloud was blocked by the Crocker Range, but rainfall continued to move forward because the atmospheric circulation was affected by Ketsana. After 0000 UTC on September 26, the rainfall intensity had decreased over the Sabah region and finally stopped.

The rainfall event (Fig. 5) occurred again over Sabah from 0415 UTC to 0615 UTC on September 26, during which the rainfall distribution pattern was almost the same as that on 2015 UTC to 2315 UTC of September 25. However, the strong circulation forced by Ketsana led the cloud to move northeastward and travel according to the Ketsana circulation pattern (2115 UTC on September 25 to 0615 UTC on September 26). Hence, the rain cloud was forced to travel through or crawl over the mountain ranges. The rain cloud was clearly trapped by the high terrain region at 0715 UTC on September 26, and the rainfall distribution patterns were based on the mountain structure. From 0815 UTC to 1115 UTC, the rain activity weakened due to the lack of water supplied over the inland region. Although the wind speed along the entire troposphere column remained strong, and high wind shear occurred at the upper level of the troposphere (Fig. 2d (ii)), the sounding data at 1200 UTC on September 26 (Fig. 2d (i)) showed that the cloud base was hanging at $874 \mathrm{mb}$ (approximately 1,226 m). The CAPE value was only $92.65 \mathrm{Jkg}^{-1}$, with a positive lift value of 0.28 . These data indicated that the thunderstorm was over. By 

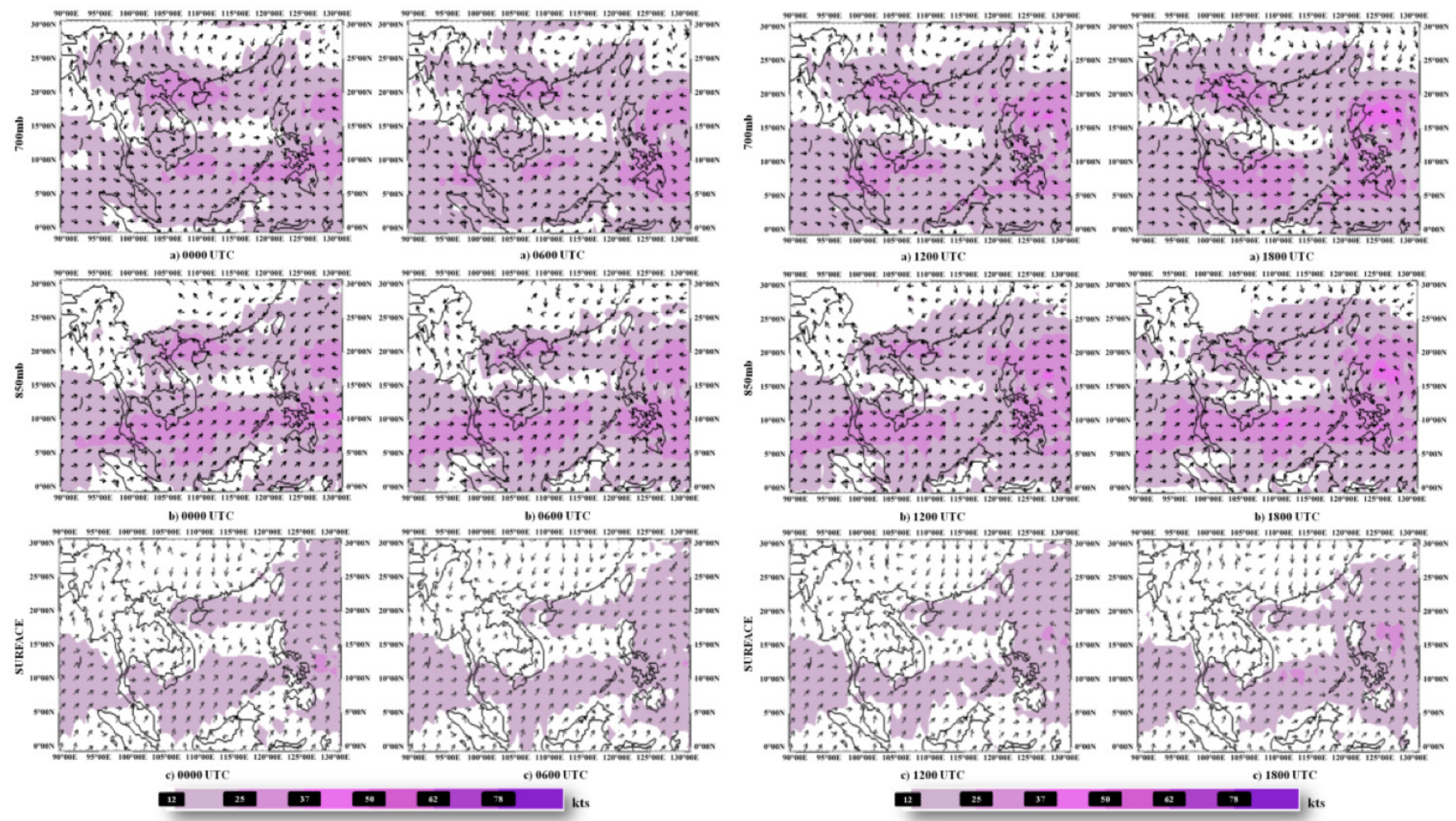

Fig. (6). Wind patterns at the pressure levels of 700 and $850 \mathrm{mb}$ and the surface in the troposphere, represented by a), b), and c), respectively. This figure shows the direction and strength of the wind for these three levels at 0000, 0600, 1200, and 1800 UTC on September 25, 2009.
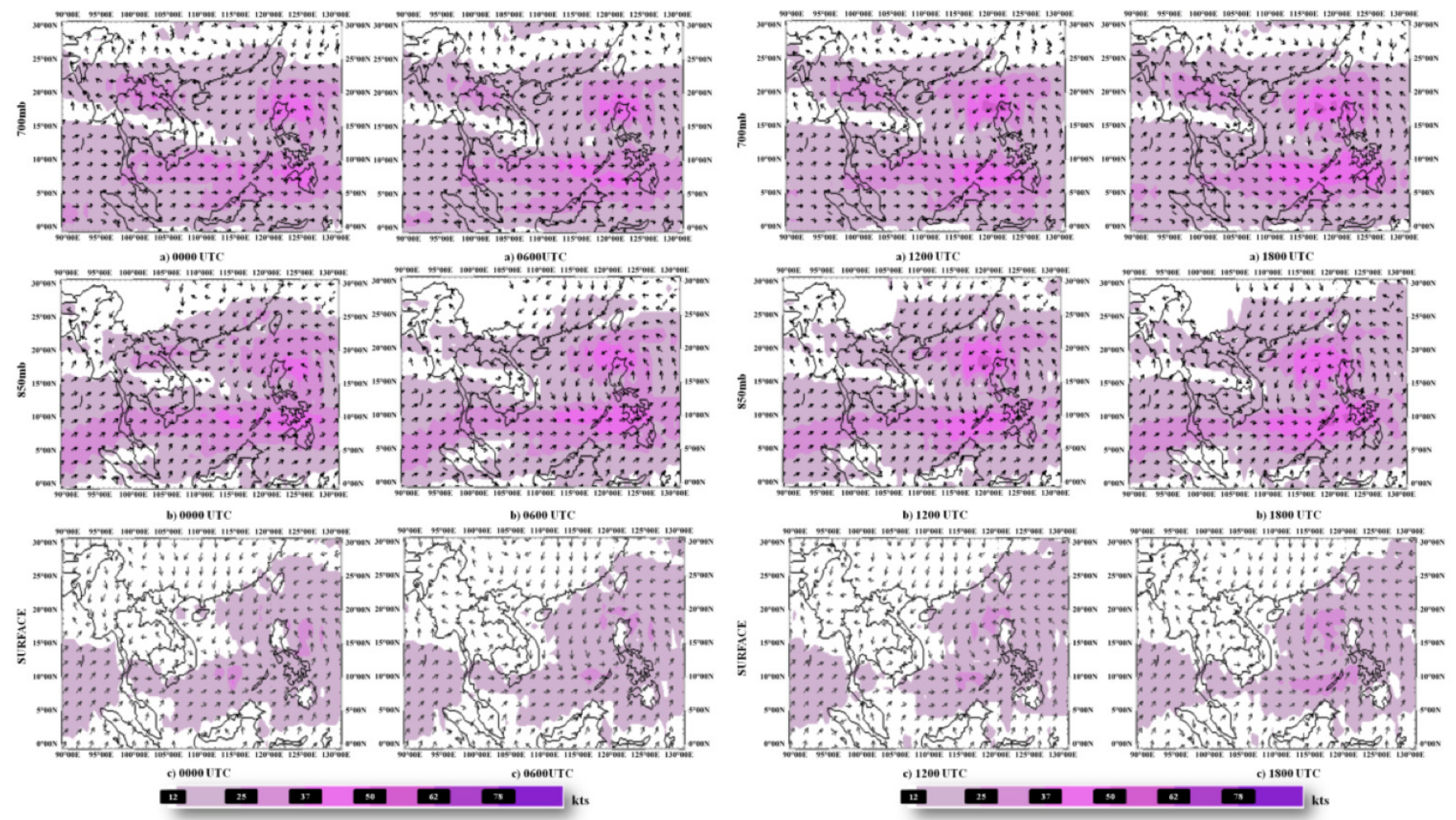

Fig. (7). Wind pattern at the pressure levels of 700 and $850 \mathrm{mb}$ and the surface in the troposphere represented by a), b), and c), respectively. This figure shows the direction and strength of the wind for these three levels at 0000, 0600, 1200, and 1800 UTC on September 26, 2009.

contrast, the weather conditions were unstable in Bintulu because the CAPE, lift, and CINS were $1,789 \mathrm{Jkg}^{-1},-3.59$, and $-29.1 \mathrm{Jkg}^{-1}$, respectively (Fig. 3d (i)). A strong veering wind also occurred at the upper level of the troposphere (Fig. 3d (ii)). Nevertheless, no rainfall occurred over the Bintulu region or even over the entire Sarawak region during 
1200 UTC on September 26. Thus, the unstable weather conditions in the Skew-T in Fig. (3d) (ii) might be due to the remaining storm energy.

Three different levels (surface, $850 \mathrm{mb}$, and $700 \mathrm{mb}$ ) of NOGAPS wind products were employed in this study to determine the wind patterns at a low level of the troposphere near EM during the early development stage of Ketsana. The wind patterns in three levels from the ground surface at different times are shown in Figs. $(6,7)$. At 0000 UTC on September 25, 2009 (Fig. 6), the surface wind over EM was less than 12 knots, and the wind direction in the $114^{\circ} \mathrm{E}$ and $2^{\circ} \mathrm{N}$ area did not follow the general wind flow over the region that moved northeastward. Over the next $6 \mathrm{~h}$, the weak surface wind of less than 12 knots remained dominant in EM, but the wind direction near $114^{\circ} \mathrm{E}$ and $2^{\circ} \mathrm{N}$ followed the wind flow northeastward toward Ketsana. At 0600 UTC, the surface wind at $116.5^{\circ} \mathrm{E}$ and $5.5^{\circ} \mathrm{N}$ tended to flow between Mount Kinabalu and Mount Trusmadi because these mountains were high enough to influence the wind direction.

The $850 \mathrm{mb}$ wind flow increased from 12 knots to 25 knots in the western part of EM at 0000 and 0600 UTC on September 25 (Fig. 6b). At this time, the wind flowed toward the low central pressure of Ketsana. At $850 \mathrm{mb}$, the wind strength of Ketsana over the east side of the Philippines was stronger than that on the surface level. The wind flow at $700 \mathrm{mb}$ showed a different wind pattern because the wind strength was similar between 700 and $850 \mathrm{mb}$ or slightly increased. The wider and stronger wind occurred at $850 \mathrm{mb}$ rather than at $700 \mathrm{mb}$. However, the wind at both levels during this period tended to flow toward Ketsana. This phenomenon might be caused by the different stages of typhoon development.

Subsequently, the surface wind during the following $6 \mathrm{~h}$ (or at 1200 UTC) did not change significantly. At 1800 UTC, the surface wind seemed to become stronger and nearer Ketsana and in several northern parts of SCS. A wind with a speed of 12 knots to 25 knots blew closer to EM, especially offshore, at the northwest of Sabah (Fig. 6c). The surface wind over $112^{\circ} \mathrm{E}$ and $1^{\circ} \mathrm{N}$ blew to the east at 1800 UTC, which might have been caused by the mountain ranges or the complicated terrains in the area; this effect mostly occurs at the surface level. The wind at $850 \mathrm{mb}$ might have also been influenced by several mountain ranges higher than this level. The wind flow at higher level did not change direction suddenly because of less friction (Fig. 6a: 1200 and 1800 UTC). During this period, the $850 \mathrm{mb}$ strong wind at 25 knots to 37 knots covered a larger area than that at 700 $\mathrm{mb}$ along the SCS and the western Pacific. However, the wind at 25 knots to 37 knots affected by Sabah at $700 \mathrm{mb}$ might have been caused by the orographic effects of the mountains listed in Table $\mathbf{1}$.

At 0000 UTC on September 26, 2009 (Fig. 7c), the surface wind over $112^{\circ} \mathrm{E}$ to $114^{\circ} \mathrm{E}$ and $1^{\circ} \mathrm{N}$ to $2^{\circ} \mathrm{N}$ blew in one direction. At 0600 UTC, the surface wind moved in the opposite direction, which was northeastward with Ketsana. The wind speed at 12 knots to 25 knots extended over EM. At $850 \mathrm{mb}$, the wind with a speed of 12 knots to 25 knots broadened and covered most of EM at 0000 UTC and the entire region at 0600 UTC. This wind became stronger and extended over SCS and the western Pacific with speeds of 25 knots to 37 knots and 37 knots to 50 knots, respectively. The wind patterns differed at $850 \mathrm{mb}$ and at $700 \mathrm{mb}$ because the wind was distributed at a very small portion over northern Sabah at $850 \mathrm{mb}$ with a speed of 25 knots to 37 knots, whereas the entire Sabah region and northern part of Sarawak was covered by this strong wind at $700 \mathrm{mb}$. Thus, winds were stronger in areas with less friction than those with high friction, such as grounds with complicated terrain. Furthermore, the atmospheric circulation was also strongly influenced by Ketsana as it developed into the tropical storm stage, which is considered to be stronger than the tropical disturbance and tropical depression stages. The wind direction at $700 \mathrm{mb}$ clearly tended to follow Ketsana's rotation pattern. The wind flow seemed to overcome the orographic effects in EM due to the strong force of Ketsana. Thus, the wind direction tended to move with the circulation without changing direction.

At 1200 UTC on September 26 (Fig. 7c), the surface wind from $112^{\circ} \mathrm{E}$ to $115^{\circ} \mathrm{E}$ and $1^{\circ} \mathrm{N}$ to $2^{\circ} \mathrm{N}$ was affected by the high-terrain regions. At 1800 UTC, the surface wind at the region from approximately $113^{\circ} \mathrm{E}$ to $115^{\circ} \mathrm{E}$ and $3^{\circ} \mathrm{N}$ and $5^{\circ} \mathrm{N}$ was affected by the mountains at Sarawak (Table 1) and then moved southeastward. The strong wind with a speed of 37 knots to 50 knots moved closer to northern Sabah at 850 $\mathrm{mb}$ and was present in $700 \mathrm{mb}$ at both 1200 and 1800 UTC. This wind affected the people of northern Sabah. The wind with a speed of 25 knots to 37 knots affected EM, especially Sabah, when Ketsana had a stronger intensity and shorter distance to EM.

Fig. (8a) illustrates that the upper-level wind at 0845 UTC on September 25, 2009 showed an irregular pattern in EM. The three mountains in Sabah (Table 1) apparently disturbed the wind movement toward the southwest direction. The high terrain inland region of Sarawak caused the wind to flow in the mountain ranges (compare Fig. 8a with Fig. 1). At 0845 UTC on September 26 (Fig. 8b), the irregular wind flow in Sabah might have been caused by the complex high terrains over the region (Fig. 1). Calm wind was observed in Sarawak at 0845 UTC, which seemed unreasonable. This phenomenon might be caused by the clear sky at that moment (because the wind track product depended on the movement of the clouds). As shown in Fig. (8c), the middle-level wind was found in EM because Ketsana, which had vertical developed clouds up to the upper troposphere, moved away from this region. The middle cloud remained in EM, whereas the middle-level wind changed direction. Fig. (8c) shows that the southwestward wind flow to the Sabah region seemed to move in between the three high mountains of Sabah and Sarawak (Table 1). The wind in the Sarawak region was weak or even calm because the wind that blew southwestward was influenced by the high-terrain regions (the yellow color regions in Fig. 1) in Sarawak and Kalimantan and tended to flow with the high-terrain structures in these regions.

Fig. (9a-d) show the cloud distribution patterns from the tail effect of Ketsana in EM from 0015 UTC on September 25 to 1215 UTC on September 26 with a time interval of 12 h. Cumulonimbus clouds were distributed offshore western 


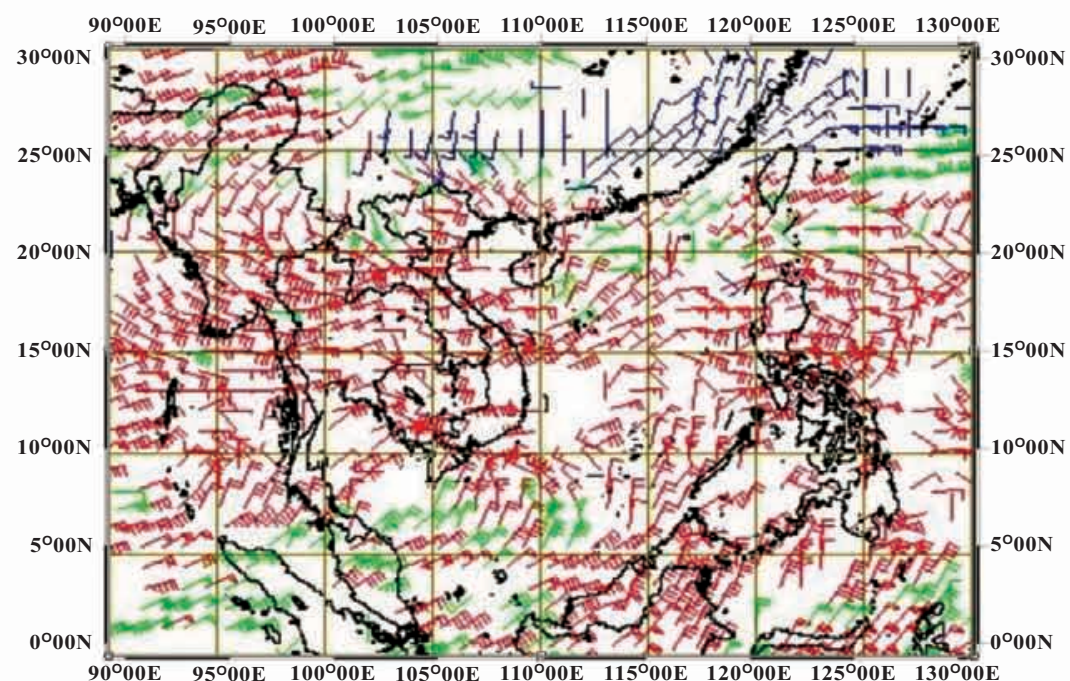

a) 25 September 2009 at 0845 UTC

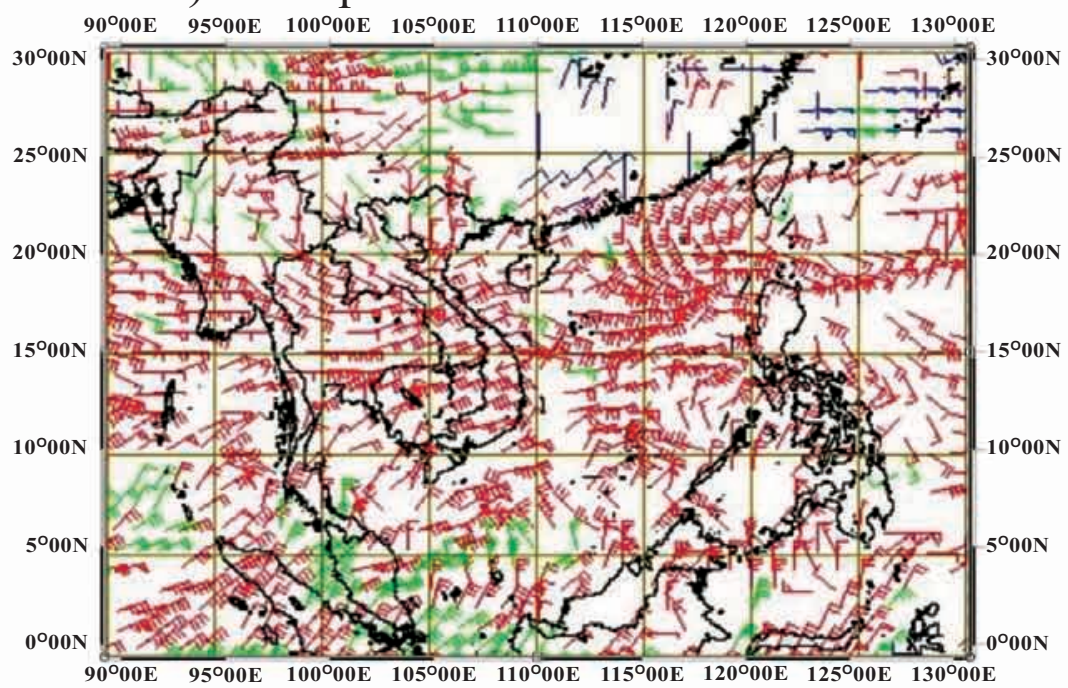

b) 26 September 2009 at 0845 UTC

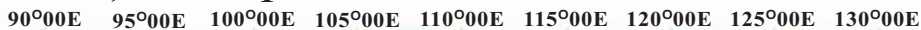

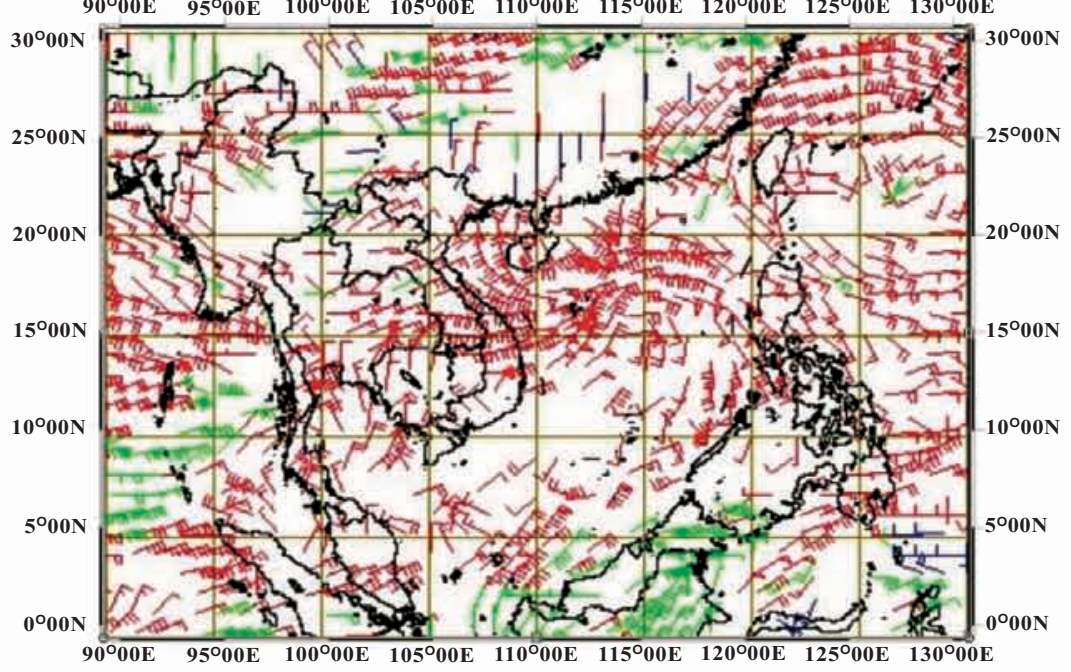

c) 27 September 2009 at 0845 UTC

Fig. (8). Atmospheric motion vector image data from September 25 to 27, 2009 at 0845 UTC. The direction and strength of the wind field are indicated by the wind barb with unit of knots. Red wind barbs represent high-level wind between 150 and $399 \mathrm{hPa}$ whereas light green and blue wind barbs indicate the moderate $(400 \mathrm{hPa}$ to $699 \mathrm{hPa})$ and low-level $(700 \mathrm{hPa}$ to $950 \mathrm{hPa})$ winds, respectively. 


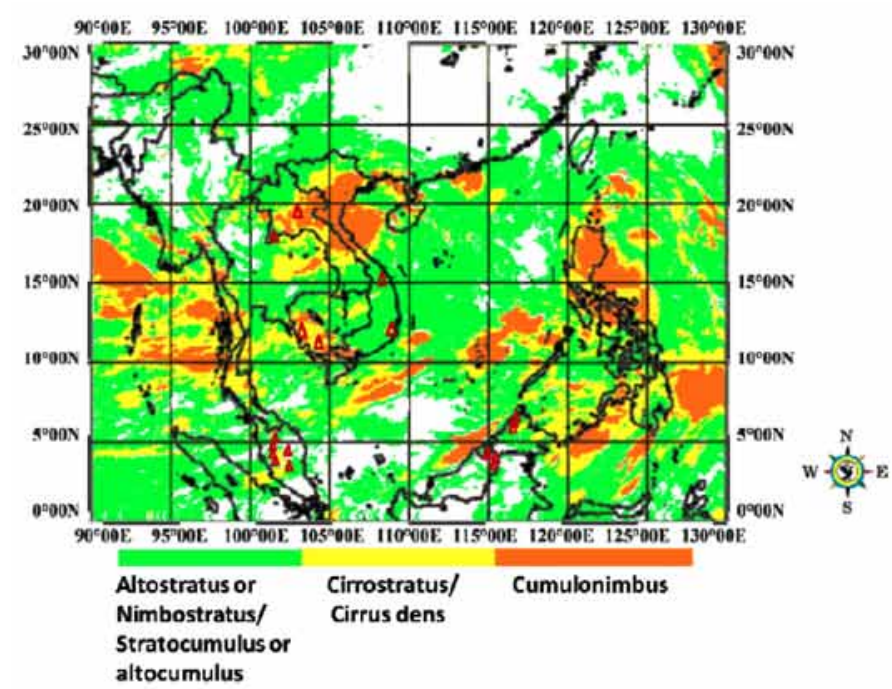

a) 0015 UTC 25 September 2011

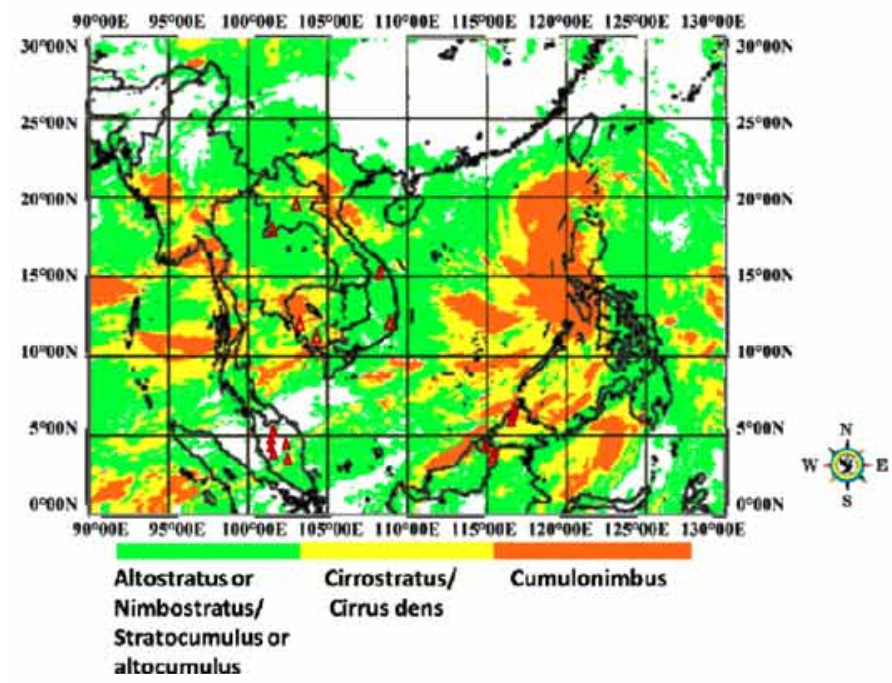

C) 0015 UTC 26 September 2011

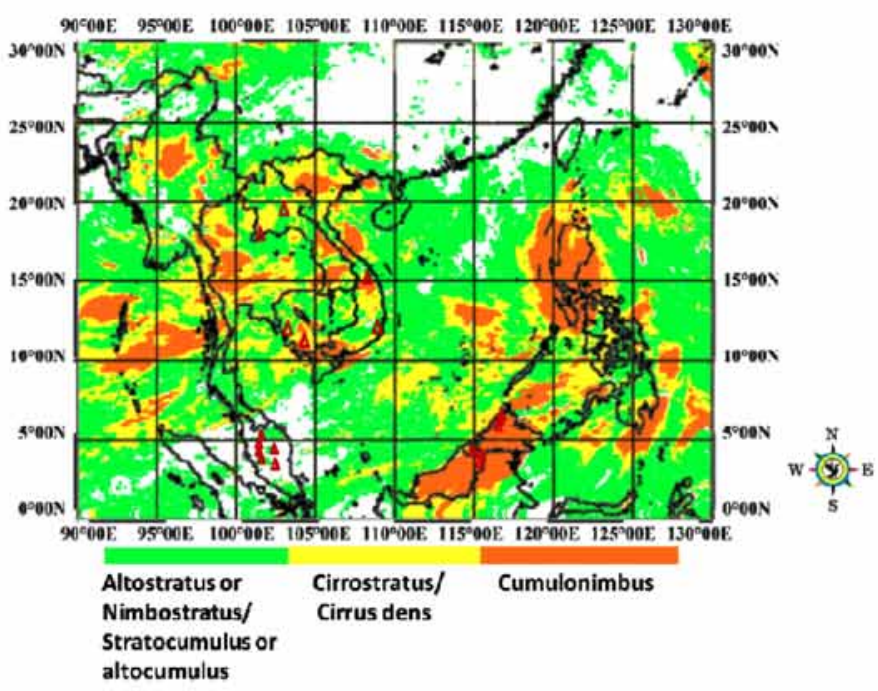

b) 1215 UTC 25 September 2011

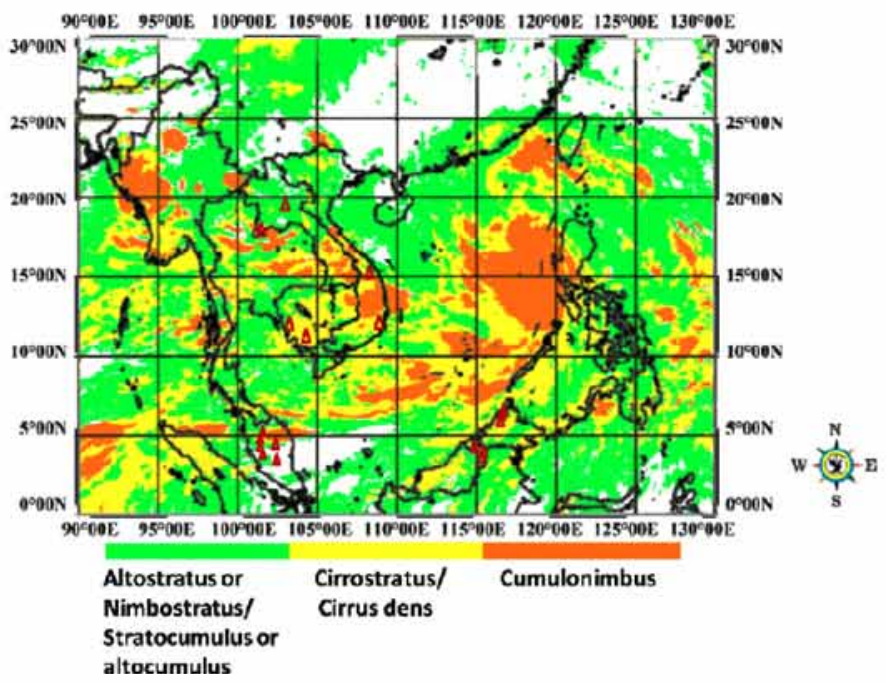

d) 1215 UTC 26 September 2011

Fig. (9). Cloud classifications during the early development stage of Typhoon Ketsana from 0015 UTC September 25, 2009 to 1215 UTC September 26, 2009, with a time interval of $12 \mathrm{~h}$, which are represented in a) to d). The red triangles in EM represent the mountains listed in Table 1.

EM (Fig. 9a). This cloud enhanced the sounding data (Fig. 2a (i)), which indicated the approach of thunderstorms. Lowand middle-level clouds were found in the Sabah region near the mountainous regions (Table 1). The thunderstorm traveled eastward and northeastward, away from the Bintulu region. Fewer low- and middle level clouds were found in the Sarawak region, which also implied that the weather conditions in the Bintulu region (Fig. 3a (i)) was more stable. High-terrain regions (in yellow; Fig. 1) caused the low- and middle-level clouds to be distributed based on the complex structure of these regions.

At 1215 UTC, cumulonimbus clouds were fully distributed over EM (Fig. 9b). This phenomenon indicated that a thunderstorm was arriving in EM that caused heavy rains due to the tail effects of Ketsana (Fig. 4). At this moment, no obvious explanation could elucidate the relationship between cloud type and orography. At 0015 UTC on September 26 (Fig. 9c), the thunderstorm passed over EM, but clusters of thunderstorms still existed offshore EM. Part of the thunderstorm affected the mountainous regions in Sabah (Table 1), and the sky in Sabah was mostly covered by high-level clouds. Low- and mid-level clouds covered most regions of Sarawak, whereas fewer high-level clouds existed in western Sarawak. High-level clouds were likely to be distributed behind the mountains, which were sheltered from the wind that blew in the northeast direction toward the center of Ketsana.

The thunderstorms that were present in the offshore waters off western EM (Fig. 9c) did not last any longer as the thunderstorm passed over the mountainous regions in EM because the tail effects of Ketsana had weakened during this period (Fig. 5). The high clouds were formed when the 
energy of the tail effects weakened, which brought cumulonimbus clouds toward Sabah and low and middle clouds in most regions. The rainfall event in EM ended at 1215 UTC on September 26 (Fig. 9d). The sounding data in Fig. (2d) (i) also support these weather conditions. Highlevel clouds remained in the Sabah mountainous region, whereas they increased in western Sarawak.

\section{CONCLUSIONS}

EM has several mountain ranges, including the Crocker Range in Sabah, which is the highest. This range affects the wind flow, cloud, and rainfall distribution patterns during severe weather, especially due to the tail effects of the typhoon. The Kinabalu, Trusmadi, and Tambuyukon mountains play an important role in affecting the weather conditions. Ketsana passed through northern EM due to the tail-end effect blown by the westerly wind that the western slopes of EM and altered the atmospheric conditions of EM, as seen in the larger amount of rainfall to western EM.

Five distinct results were found for this cloud and rainfall-orography interactions during the typhoon activity. First, portions of the clouds were blocked by the western Crocker Range, which caused the rainfall event to slow down temporarily in the western region of EM. Second, heavy rainfall occurred around the western mountain ranges of EM. Third, when the rainclouds were sufficiently high and an extra energy source existed (typhoon system) occurred, the rainfall process were forced to move forward, pass over EM, and then reach the eastern side of the mountain ranges. Fourth, the variation of the cloud and rainfall distribution pattern was related to the shapes of the mountains. Lastly, the heavy rainfall distribution was significantly more affected by the high mountains close to the shoreline than by the interior region of the island.

The interaction of a meteorological disturbance (such as typhoon) and orographic effects was discussed in this study. The focus of this study was to determine the influences of this disturbance (tail-end effect) on the regional environment. The complexity of mountain distribution causes a multitude of effects on the weather because this study not only showed orographic effects as stated in above paragraph but also the normal rain shadow effect caused by the mountain (such as Foehn or Chinook phenomenal) was not found in this case since the tail end effect of typhoon further intensified the rainfall event over the mountain owing to orographic lifting, and the strong circulation of tail end effect caused the intensified rainfall event to move over the mountain and continued to move for more than $100 \mathrm{~km}$ away from the mountain before drying out due to lack of water vapour supplied. Therefore, this study provided better understanding on the effects of orography on the tail-end effect of typhoon in EM. Studies on typhoon systems and their impacts on orography should be further explored to increase the accuracy of the results on the tail-end effect of typhoon on EM.

\section{CONFLICT OF INTEREST}

The authors confirm that this article content has no conflict of interest.

\section{ACKNOWLEDGEMENTS}

The author would like to thank the Institute of Postgraduate Students of Universiti Sains Malaysia for the Postgraduate Research Grant Scheme (Grant No. 1001/PFIZIK/833033) and gratefully acknowledge the financial assistance from the RU grant (Account number: 1001/PFIZIK/811152) and short-term USM grant (Account number: 304/PFIZIK/6310057). My sincere gratitude goes to my fellow USM postgraduate students who helped me carry out this project. I appreciate the help from NASA for providing free ASTER GDEM data. My appreciation also goes out to the staff of the China Meteorological Administration for their generosity on sharing valuable satellite data. My thanks are also extended to the University of Wyoming, which provided public access to radiosonde data.

\section{REFERENCES}

[1] Neumann CJ, Holland GJ. Global Guide to Tropical Cyclone Forecasting, Chapter 1: Global Overview, 1993. [Online]. Available on: http://cawcr.gov.au/bmrc/pubs/tcguide/globa_guide_ intro.htm [Accessed: 7 July 2011].

[2] US. Naval Maritime Forecast Center/ Joint Typhoon Warning Center Pearl Harbor, Hawaii. Ann Trop Cycl Rep; 1959-2008.

[3] Elsner JB, Liu KB. Examining the ENSO-typhoon hypothesis. Clim Res 2003; 25(1): 43-54.

[4] Benfield A. Annual global climate and catastrophe report. Impact Forecast 2009; p. 66.

[5] Ariffin M, Moten S. The impact of tropical cyclones in the western pacific ocean and south china sea on the rainfall in Malaysia. Malaysia: Malaysia Meteorological Department (MMD) and Ministry Of Science Technology And Innovation (MOTIS) 2009; Res Pub No.5, 2009.

[6] Ariffin M, Moten S. The impact of tropical cyclone in the bay of bengal on the rainfall in peninsular Malaysia. Malaysia: Malaysia Meteorological Department (MMD) and Ministry Of Science Technology And Innovation (MOTIS) 2009; Res Pub No.7, 2009.

[7] MOTIS. ESCAP/WMO Typhoon Committee $42^{\text {nd }}$ Session, Malaysia. Member Report 2009.

[8] MOTIS. Laporan Ribut Petir dan Hujan Batu yang Berlaku di Daerah Bera dan Daerah Lain di Negeri Pahang pada 28 September 2009. 2009 (Malay version).

[9] MOTIS. Report on strong winds occurrence in The West of Sabah on 27 September 2009. 2009.

[10] Woodson KW. Sky surfing! The thrill of catching a 'Wave' 12,000 feet above the snows of Mauna Kea. Hawaii: Honolulu Magazine 1969.

[11] Brown GZ, DeKay M. Sun, wind \& light: architectural design strategies, J. US: Wiley 2001.

[12] Oke TR. Boundary layer climates. London: Routledge 1988.

[13] Crawley SW, Dillon RM. Steel buildings: analysis and design. US: Wiley 1993.

[14] Thompson RD. Atmospheric processes and systems. London: Routledge 1998.

[15] Harrison RM. Understanding our environment: an introduction to environmental chemistry and pollution. London: Royal Soc Chem 1999.

[16] Wu CC, Yen TH, Kuo YH, Wang W. Rainfall simulation associated with Typhoon Herb (1996) near Taiwan. Part I: The topographic effect. Weather Forecast 2002; 17: 1001-15.

[17] Frank R, Fabrice CM, Antoine LB, Olivier N. Structure and evolution of intense tropical cyclone dina near La Réunion on 22 January 2002: GB-EVTD analysis of single doppler radar observations. J Atmos Oceanic Technol 2004; 21: 1501-18.

[18] Lin YL, Chen SY, Hill CM, Huang CY. Control parameters for the influence of a mesoscale mountain range on cyclone track continuity and deflection. J Atmos Sci 2005; 62: 1849-66.

[19] Jian GJ, Wu CC. A numerical study of the track deflection of super-typhoon Haitang (2005) prior to its landfall in Taiwan. Mon Weather Rev 2008; 136: 598-615. 
[20] Pan CJ, Reddy KK, Lai HC, Yang SS. Wind profiler observations on orographic effects of typhoon wind structure modification over Taiwan $\left(120.38^{\circ} \mathrm{E}, 22.6^{\circ} \mathrm{N}\right)$. Ann Geophys 2010; 28: 141-7.

[21] Wu CC, Kuo YH. Numerical simulation of Typhoon Gladys (1994) and its interaction with Taiwan terrain using the GFDL hurricane model. Mon Weather Rev 2001; 129: 1533-49.

[22] Witcraft NC, Lin YL, Kuo YH. Dynamics of orographic rain associated with the passage of a tropical cyclone over a mesoscale mountain. J Terr Atmos Ocean Sci 2005; 16(5): 1133-61.

[23] Smith II BL, Lin YL, Reeves HD. Effects of cyclone track on precipitation distribution along the California coastal range and Sierra Nevada. 12th Conf. on Mountain Meteorology; 2006 Aug 28-Sept 1; Santa Fe, NM, 2006.

[24] Tanaka K, Kamohara S, Yamada F, Ohmoto T, Sugio S. Orographical effects of heavy rainfall by typhoon 0514 (NABI). Nat Hazards Rev 2008; 9(4): 190-8.

[25] Cheung KKW, Huang LR, Lee CS. Characteristics of rainfall during tropical cyclone periods in Taiwan. Nat Hazards Earth Syst Sci 2008; 8: 1463-74.

[26] Yue C. Quantitative analysis of torrential rainfall associated with typhoon landfall: a case study of typhoon Haitang (2005). Prog Nat Sci 2009; 19: 55-63.

[27] Colón-Pagán IC. Orographic effects on rainfall induced by the passage of tropical cyclones over mountainous islands: Part I: the effect of cloud microphysics. US: Colón-Pagán, SOARS 2009; pp. $1-25$.

[28] Huang YH, Wu CC, Wang Y. The influence of island topography on typhoon track deflection. Mon Weather Rev 2011; 139: 170827.

[29] Yen TH, Wu CC, Lien GY. Rainfall simulations of Typhoon Morakot with controlled translation speed based on EnKF data assimilation. Terr Atmos Ocean Sci 2011; 22: 647-60.
[30] Liang JL, Wu L, Ge X, Wu CC. Monsoonal influence on typhoon morakot (2009). Part II: Numerical Study. J Atmos Sci (in press) 2012; 68: 2222-35.

[31] Tan F, Lim HS, Abdullah K. The effects of orography in indochina on wind, cloud, and rainfall patterns during typhoon ketsana (2009). Asia-Pacific J Atmos Sci 2012; 48(3): 295-314.

[32] Aadet. "East Malaysia," 13 June 2011. [Online]. Available on: http://www.aadet.com/article/East_Malaysia.

[33] Sarawak_Govermment_Portal. "The Geography of Sarawak," 13 June 2011. [Online]. Available on: http://www.sarawak.gov.my /en/about-sarawak/geography

[34] FengYun 2C satellite service products (application manual in chinese version). China: China Meteorological Administration (CMA) 2009.

[35] Groenemeijer P, Punkka AJ, Teittinen J. "Instability: Forecasting Severe Convective Storms," Oct 2011 [Online]. Available on: http://www.estofex.org/guide/1_2_2.html

[36] Haby J. Skew-T: a look at CINH, 4 Sep 2011. [Online]. Available on: http://www.theweatherprediction.com/habyhints/306/

[37] Davies JM. Hurricane and tropical cyclone tornado environments from RUC proximity sounding. Preprints, $23^{\text {rd }}$ Conf. Severe Local Storms, St. Louis, MO, Am Meteor Soc 2006; P8.1.

[38] Davies JM. Total CAPE, low-level CAPE, and LFC in significant tornado events with relatively high LCL heights. Preprints, $23^{\text {rd }}$ Conf. Severe Local Storms, St. Louis, MO, Am Meteor Soc 2006; pp. 1-3.

[39] Davies JM. Estimations of CIN and LFC associated with tornadic and nontornadic supercells. Weather Forecast 2004; 19: 714-26.

[40] Peakware. "World Mountain Encyclopedia," 13 June 2011. [Online]. Available on: http://www.peakware.com/peaks.html? choice= AsE).

[41] GeoNames. "Vietnam - Highest Mountains," 13 June 2011. [Online]. Available on: http://www.geonames.org/countries/

(C) Tan et al.; Licensee Bentham Open.

This is an open access article licensed under the terms of the Creative Commons Attribution Non-Commercial License (http: //creativecommons.org/licenses/by$\mathrm{nc} / 3.0 /$ ) which permits unrestricted, non-commercial use, distribution and reproduction in any medium, provided the work is properly cited. 